Portland State University

PDXScholar

Summer 11-7-2014

\title{
"Your information station": A Case study of rural radio in the 21st century
}

William Jacob Amadeus Pinnock

Portland State University

Follow this and additional works at: https://pdxscholar.library.pdx.edu/open_access_etds

Part of the Communication Commons, and the Radio Commons Let us know how access to this document benefits you.

\section{Recommended Citation}

Pinnock, William Jacob Amadeus, "'Your information station": A Case study of rural radio in the 21st century" (2014). Dissertations and Theses. Paper 2115.

https://doi.org/10.15760/etd.2113

This Thesis is brought to you for free and open access. It has been accepted for inclusion in Dissertations and Theses by an authorized administrator of PDXScholar. Please contact us if we can make this document more accessible: pdxscholar@pdx.edu. 
"Your information station": A Case study of rural radio in the $21^{\text {st }}$ century

by

William Jacob Amadeus Pinnock

A thesis submitted in partial fulfillment of the

requirements for the degree of

\author{
Master of Science \\ in \\ Communication
}

Thesis Committee:

Cynthia-Lou Coleman, Chair

Lee Shaker

Robert Liebman

Portland State University

2014 
(C) 2014 William Jacob Amadeus Pinnock 


\begin{abstract}
The study examined how the introduction of high-speed internet into a rural community affected audience members' use of their local radio station. A qualitative case study was guided by uses and gratifications and niche theory. The author conducted interviews with KMMR FM audience members in Malta, Montana, to investigate how the introduction of high-speed internet impacted listener habits. Twenty participants who either listened to or produced content for KMMR FM were interviewed. The author performed a thematic analysis of different uses for the radio guided by typologies created by Rubin (1983), Palmgreen and Rayburn (1979), and Katz, Haas, and Gurevitch (1973). The results showed the internet and the radio gratify different needs for audience members: radio was used the most for local information and the internet for more specialized needs that could not be met by the radio. The findings also showed that the radio is important in fostering a sense of social cohesion within the community.
\end{abstract}

Key words: Hi-Line, internet, Montana, niche theory, rural radio, uses and gratifications 


\section{Dedication}

This thesis is dedicated to the memory of Victoria Marie Holden-Smith, Ph.D (1945-2008). Dr. Holden-Smith was an advocate of the First Amendment and a supporter of independent publishing, independent broadcasting, and independent thinking. She was my catalyst for pursuing a Master's degree in Communication and my undergraduate career would have suffered without her guidance, wisdom, and sharp sense of humor. Her passing was a great loss not only for the University of North Dakota and its students, but also for the academic world. She has been, and will continue to be, greatly missed. 


\section{Acknowledgments}

This thesis would not have been possible without the guidance and support of the faculty at Portland State University, my family, and my friends.

I would first like to thank Dr. Cynthia-Lou Coleman whose patience with me I cannot begin to fathom. She has been a source of pride to have on my committee and I could not ask for a better Chair. I would also like to thank Dr. Lee Shaker, who helped reignite my passion for local media and the importance it has on communities. I would also like to thank Dr. Robert Liebman, who guided me through the complex world of qualitative methods and allowed me the opportunity to work with him on a qualitative research project. And a special thanks to Dr. Jeffrey Robinson, who has looked out for me since I started this educational expedition four years ago.

I would be a horrid son if I did not give my parents the praise they deserve. Throughout my life they have provided me with unconditional love and support, sometimes at the expense of their own happiness. This degree hopefully will show them that I have not been goofing off during my eight years of college.

I would also like to thank my brother Thomas George Pinnock IV and my sister Anna Byrne who have stuck up for me throughout my life and provided love and support. You two are pretty alright in my book.

I also want to thank Greg and Claudette Kielb for their consent in allowing me to study KMMR radio. Greg, Claude, and KMMR have been important to me since I was a teenager and I hope sharing KMMR with the world will show others the uniqueness of KMMR. I would also like to thank Joyce Robinson and Kelly Korsbeck who took the 
time to talk with me about being a DJ in a rural Montana town. In addition, I would like to thank the town of Malta, my informants, and those who allowed me to interview them. I could not have asked for a better field research site or a better set of people to talk to or interview.

I would finally like to thank all of my friends who, at one point or another, have listened to me talk about radio, spew hatred of smart phones, or talk at length about my distaste of coupons and crock pots. Every last one of you has provided me with an unquantifiable amount of joy. Special thanks to MJ Dunne for helping me keep my head on straight when I was a stranger in a strange land, Erik Bergstrom for providing me with a safe haven in Minneapolis, Minnesota, when the harsh realities of Portland were too much, and Brian Strandberg, Kaleigh Lindholm, Greg Jans and John Meyers for their random trips to Portland. 


\section{Table of Contents}

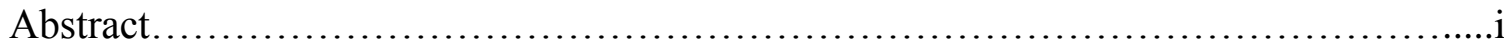

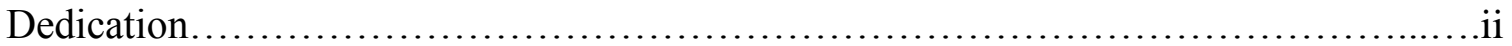

Acknowledgements.........................................................

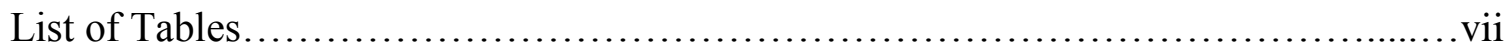

Chapter 1

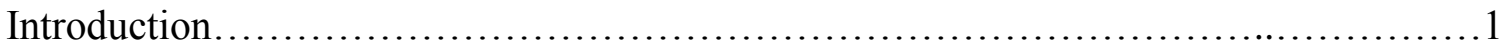

Chapter 2

Relevant Literature................................................................

Chapter 3

Methodology.................................................................... 27

Chapter 4

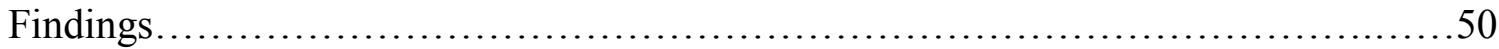

Chapter 5

Discussion and Conclusion.................................................. 92

References.............................................................. 104

Appendices

A. Station Owner Interview Questions................................. 109

B. Disc Jockey Interview Questions...................................111

C. Audience Member Interview Questions.............................113

D. KMMR Owner Recruitment Script.................................115

E. Disc Jockey Recruitment Script................................... 117 
F. Audience Member Recruitment Script...................................119

G. Station Owner Informed Consent...................................120

H. Disc Jockey Informed Consent.........................................122

I. Audience Member Informed Consent...................................125 


\section{List of Tables}

Table 1

Gratifications Sought by KMMR Listeners.........................................59

Table 2

Gratifications Obtained by KMMR Listeners....................................65

Table 3

Type of Information KMMR Users Obtained....................................67 


\section{Chapter I}

\section{Introduction}

\section{Introduction}

Cities offer many outlets for mass communication: television stations, daily newspapers, community newspapers, radio stations, and the internet with its various blogs and websites chronicling the urban experience. In this environment, an individual is able to connect to a local media outlet that best suits his or her needs due to the abundance of media sources. In rural communities however, there are often fewer choices of local media. Rural communities (conceptualized for this project using the USDA's definition as towns with population sizes of 2,500 or less and are located outside of larger metropolitan areas) often do not have their own television stations (Cromartie \& Parker, 2012). As a result, news broadcasts they receive come from larger cities that may not cover local events. Rural communities often have local newspapers, but they are typically printed once a week and do not provide, as television stations and websites can, up-to-the minute information about local events. And while rural communities in North America are starting to receive more internet access, there are still areas that go without high-speed internet and have to rely on dial-up access to the internet (Knight Commission, 2011).

What options do these rural areas have to stay connected to local events and have programming central to them? One answer lies in the local radio station which provides much needed social, political and economic information specific to its locale (Schramm, 1964). 
The current project examines the uses (why audiences seek out certain media) by community members and the gratifications (what needs audience members fulfill) they receive from a rural radio station located in the Hi-Line of Montana and the types of gratifications producers of the station hope they fulfill with their programming.

\section{Purpose}

The purpose of the current study is to examine the production and consumption of a local radio station's programs within the framework of uses and gratifications theory and niche theory. The researcher examines three areas of interest: the first is production of programs and the expected gratifications the producers feel their programs offer the community. The second is the consumption of radio broadcasts, and more specifically, what gratifications the audience members seek and obtain from listening to the station. The third interest is the impact that the introduction of high-speed internet into the rural community has had on community members' use of their local radio station.

The goals of this research are to chronicle the production and consumption of programming within the framework of uses and gratifications theory and the potential impacts the internet has had on the listenership of radio station KMMR in Malta, Montana, through niche theory. For the current project, uses and gratifications and niche theory served as a way to understand how the changing media environment has impacted listener habits and how media producers are handling the change.

\section{The Hi-Line of Montana}

The Hi-Line is the northern third of Montana that runs along the Canadian border and stretches from the North Dakota border (eastern Montana) along Highway 2 (parallel 
with the railroad) to the Western part of the state ending at the foothills of the Rocky Mountains (Quammen, 2012). The Hi-Line region is "26 million acres of...mostly semiarid plains" populated with small towns along the railroad tracks where the main industries are farming, ranching and oil/gas production (Quammen, 2012, paragraph 1). The landscape of this region is comprised of large hills covered in sage brush and prairiedog mounds. Beneath these hills, yellow and green alfalfa fields dance when the wind rushes through them. Along highways and dirt roads, clusters of cottonwood trees surrounding farm houses punctuate the landscape. Irrigation canals delivering water to farmland border highways and fields. Dust is ever present with the abundance of country dirt roads leading to farm houses and fields. Cows and sheep can often be found grazing in the hot sun or cooling off near water. Trees border the muddy Milk River as it snakes along the path carved out by the Ancient Missouri River, and while the towns are many (vestiges from the golden age of railroads), people are few and far between.

Many Hi-Line towns are hundreds of miles away from any of the larger cities in Montana such as Great Falls, Billings, Missoula, Helena, and Bozeman, and because of the lack of proximity to larger cities, many rural communities along the Hi-Line often have their own radio stations which play a vital role in informing and entertaining their communities and the surrounding areas.

For this project, I selected KMMR in Malta, Montana, due to its similarity to other rural communities on the Hi-Line and because of my personal relationship with the town. The following reasons are why I chose Malta: 1) I grew up in Malta, worked at KMMR, and I have a personal relationship with the owners of KMMR and townspeople, 
2) Malta is similar in size to many of the Hi-Line communities, 3) it has a radio station, 4) farming and ranching are the main industries with oil and natural gas production becoming more prevalent (Quammen, 2012), and 5) with the exception of smaller communities located outside of Great Falls, Montana, Malta is a two-hour or more drive to reach a city with a population of over 50,000 people.

Malta is like other rural communities because news broadcasts on television (out of Great Falls or Billings) or printed in the larger daily newspapers (The Great Falls Tribune and The Billings Gazette) do not report on topical issues that are specific to rural communities, with the exception of catastrophic events (flood, murder, large scale theft, etc.) or an event which has the potential to impact the entire state (forest fire, flood, sporting events, etc.). Another factor of Malta's isolation is the sporadic delivery of state newspapers to rural communities like Malta. In order for Malta to receive The Billings Gazette or The Great Falls Tribune, newspaper deliverers have to drive to Malta (a threehour or longer drive from Great Falls or Billings to Malta) to deliver the newspapers for distribution.

Due to the small population size and limited advertising opportunities to help fund larger scale printing or broadcasting operations, rural communities rely on small local radio stations which broadcast news and entertainment which is specific to its community.

\section{Malta, Montana}

Founded in 1887 and originally known as "Siding 54," Malta was a minute railroad community located in the north-eastern plains of Montana, and eventually gained 
its name after a blind-folded employee of the St. Paul, Minneapolis, and Manitoba Railway spun a globe and laid his finger upon it (Costello, 1962). In its early years, Malta was a railroad and cattle town, with cattlemen being the first to settle into the area in 1892 (Costello, 1962). In 1909, Malta became incorporated and had a population of 500 people. In 1910, farmers started settling into the area because of the promise of open land. In 1915, Phillips County was created and Malta would eventually become the county seat. By 1920, Phillips County had a population of 9,000 people and with the Great Depression in the 1930s, more farmers were attracted to the area with the promise of land. By the 1970s, farming and ranching were still staples of the community, but natural gas production had started to boom. In the 1990s, the Zortman gold mine closed down, resulting in a loss of jobs for the community and many people moving out of Malta in order to find work.

Today, Malta remains a small, quiet farming and ranching community with a population of 1,997 (US Census, 2013). It is a town where in the morning elderly individuals get coffee at the one of the local cafes and at night, teenagers take to their vehicles to cruise on Central Avenue from the West-Side Self Service convenience store to the defunct Joe's In and Out burger shack. It is a community where the county fair and local sporting events are the biggest events of the year. It is a community where everyone waves from their vehicle, even if they do not know you. It is also a town where everyone knows everyone and secrets are in short supply. It is also a town with a strong commitment to community support, as evidenced by fundraisers put on by KMMR FM to help support local individuals needing medical help or the yearly fundraiser for the 
Fourth of July fireworks display. These aspects of Malta have not changed since I first left Malta in 2005, and from my experience going back to Malta in 2013, it looks like they are not going to change anytime soon.

\section{KMMR}

KMMR is a privately owned commercial radio station servicing Malta, Montana, and the people of Phillips County. KMMR is owned by husband and wife Greg and Claudette Kielb of Malta and aired its first broadcast at 1:58 p.m. on September 26,1980. Prior to the Kielbs' ownership, KMMR was a satellite station for KLTZ out of Glasgow, Montana. In 1974, Greg and Claudette moved to Malta from St. Paul, Minnesota, where Greg had graduated from Brown Institute, a broadcasting school in Minneapolis, Minnesota, to take over operations at KLTZ's satellite station in Malta. It was in 1976 when the owner of the station told Greg he was considering putting in an FM station in Malta and asked Greg if would be the manager of the station.

Although many thought that it was not economically feasible to have a local radio station, KMMR 100.1 FM has been a staple in Malta, "There were definitely doubters, they loved the idea of a radio station in Malta, they didn't think economically it could last, some said it would not last two years, I was told that several times" (Greg Kielb, 2013). From 1980 to 1995 KMMR was owned by three individuals: Greg Kielb, Claudette Kielb, and their business partner. In 1995, Greg and Claudette bought their business partner's shares of KMMR Inc. to become the sole owners of KMMR.

The operation of KMMR is comprised of local residents: Greg who handles many of the on-air duties associated with the station such as program selection, program 
creation, interviews for local segments, advertisement creation, writing news stories, hosting local events, on-air sports broadcasts, and other day-to-day activities. Claudette Kielb manages the bookkeeping. KMMR has an advertising team that sells advertisement spots, records advertisements for broadcasting, and assists in program production. KMMR has two full time disc jockeys at the time of this writing: Joyce Robinson is the voice of the morning shift (5:45 a.m.-12:00 p.m.) and Kelly Korsbeck runs the afternoon shift (12:00 p.m.-6 p.m.). The evening shift (6:00 p.m.-10:00 p.m.) is comprised of parttime employees who are residents of Malta.

The format of KMMR is contemporary country-western Monday through Thursday from 6:00 a.m. to 6:00 p.m. and classic pop and rock from the 1960s, 1970s, 1980s, and 1990s from 6:00 p.m. to 10:00 p.m., with weekends having classic pop and rock beginning at noon. KMMR produces several of its own programs such as Coach's Corner, local news, sports and weather reports, sporting events, church services, What's Happening, Dog Gone Gone Dog Show and radio-thons. In addition to its locally produced material, KMMR airs regionally produced programs from the Northern Broadcasting System out of Billings, Montana, such as Northern Ag News, Voices of Montana, Northern Sports Network, and Denver Broncos Football and nationally syndicated programs such as The Huckabee Report, ABC World News, Rick Dees and the Weekly Top 20, and Under the Hood. KMMR has a web presence which provides a link to live sporting events and connects listeners to the Northern Broadcasting System's website. KMMR also subscribes to the AP Newswire and mixes both locally produced 
and regionally produced materials for their newscasts and AP Scoreboard (national and regional sports scores) updates.

\section{Researcher's Relationship to KMMR}

I grew up in Malta, Montana, where I attended high school and worked at KMMR from 2002 through 2005 as a disc jockey. My shifts were 6:00 p.m. to 10:00 p.m. or 11:00 p.m. (on Fridays or Saturdays) and I also worked daytime shifts on weekends and would fill in morning and daytime shifts during the weekday when I was not in school. My on-air duties included reading news and weather reports, choosing music to broadcast, queuing programs to air, reading live advertisement spots, taking requests from our phone-line, and announcing songs. At KMMR I was not only an on-air disc jockey, I was also an information source for residents who would call or visit the station if they missed a weather report, wanted sports scores, wanted to know the time of a program, wanted the name of a musical artist, or needed information about road closures. When I worked at KMMR, their motto "Your Information Station" neatly summed up the role of the station in the town by providing the local community with information that was relevant and important.

My experiences with KMMR led me to ask how radio producers and audience members understand the role the station plays and what impacts have resulted from the introduction of a high-speed internet. With more connections between the rural communities and urban centers, would there be a reduction in time spent with the radio, an older, more established medium, would the internet have little impact on audience 
members' use of their local station, or would both mediums have carved out different niches for themselves by offering different gratifications? 


\section{Chapter II}

\section{Relevant Literature}

\section{Uses and Gratifications}

Why people use the media and what they receive from media are the foundations of uses and gratifications theory. Prior to uses and gratifications and the limited effects research, the hypodermic needle model posited that the media and audiences were in a near Orwellian relationship: audience members were passive recipients susceptible to any messages put forth by the media. This pessimistic and grandiose view of media and audience relationships eventually sparked an era of research dubbed "limited effects." The limited effects model argues that the media are not all controlling, that audiences have free-will in media choices, and that the audience has the cognitive ability to critique what it is given. This paradigm shift from the hypodermic needle model to limited effects sparked the era of uses and gratifications research which tried to explain why people choose certain media and what they receive from it.

Uses and gratifications research was spearheaded by Elihu Katz in the late 1950s when he argued that researchers needed to start asking not just "What does media do to people?" but "What do people do with media?" (as cited in Sparks, 2012). Prior to Katz, many researchers had examined the idea of what people do with media: Herzog's (1944) study on the use of radio soap operas, Field and Lazarsfeld's (1946) large scale study on radio use in America, Berelson's (1949) study on the response to a newspaper strike in New York, and Wolf and Fiske's (1949) study on comic books and ego development. It was with the publication of Personal Influence (1956) by Elihu Katz and Paul Lazarsfeld 
that created a large-scale paradigmatic shift within the social sciences. Katz and Lazarsfeld argued that "selective exposure, perception, and retention" guarded individuals from the totalitarian effects of mass media (Ball-Rokeach, 1998, p.7). In their view, the media were not in control of the population, but instead, the population was in control of what they were exposed to and media did not necessarily gratify everyone's needs the same way.

Uses and gratifications is a social-psychological theory which states that users of media actively seek out and use media to fulfill specific needs. In order to understand the audience, a researcher must understand reasons behind audience members' choice of media (Rubin, 1993). When audience members approach media they are doing so to fulfill a social and/or psychological need (Palmgreen \& Rayburn, 1979). The media landscape is comprised of many choices for individuals and uses and gratifications theory states that media must compete for people's attention (Sparks, 2012). It is imperative for scholars of uses and gratifications to understand why some mediums are chosen over others: what does one medium offer an individual that another medium cannot and what gratifications emerge from one medium that are unavailable from another?

When asking why people make these choices, it is important to understand what needs people are gratifying. Although scholars for three decades had been researching why people were actively seeking out media, no general typology of what gratifications are fulfilled by the media had arisen . McQuail, Blumler, and Brown (as cited in Katz, Blumler \& Gurevitch, 1973) rectified this by defining four distinct categories of gratifications that had permeated throughout uses and gratifications research: 
1. Diversion is escaping from routines or problems, media as tool of escape;

2. Personal relationships are us the media as a companion, but also can provide useful conversation pieces;

3. Personal identity is self-esteem and value reinforcement;

4. Surveillance is exploring the media environment in order to gain understanding of a location or people.

Katz, et al. (1973) provided insight into Mcquail, et al.'s (1972) typologies by explaining the psychological needs which could be associated with each aspect of their typology. Diversion or escape could derive from a need to "release tension and reduce anxiety," personal relationships (also known as social utility) could stem from a need to feel affiliation, the gratification of personal reference could come from a need to uphold one's self esteem or to reinforce existing beliefs, and surveillance could be used in an attempt to understand an individual's environment (physical or sociological environment (Katz, et al., 1973, pp. 513-514). While Katz, et al. (1973) captured a general understanding of the reasons for media use, Rubin (as cited in Sparks, 2012) created a more encompassing eight category typology for television use to give more descriptive power to uses and gratifications scholars:

1. Passing time using media to divert attention;

2. Companionship using media as an outlet for spending time with others;

3. Escape using media as a way to relieve pressure or anxiety;

4. Enjoyment using media to have a pleasurable experience;

5. Social Interaction using media to be able to have conversations with others; 
6. Relaxation using media to feel calmed;

7. Information using media to learn about what is going on in the world;

8. Excitement using media to feel excited.

Although typologies are useful in understanding what an individual gains from media, it is important to consider the relationship between a medium and its audiences. If an individual is engaging with a medium as, for example, a church member, researchers can "gain insight into the relationship between the attributes of the media (real or perceived) and the social and psychological functions which they serve" (Katz, et al., 1973, p. 165). Real or perceived assessments are the glue that binds an audience member to a particular medium. For example, the attributes of talk radio (open-microphone and audience participation) allow for a participant-style of programming, with individuals often being information seekers who are more community-minded (Surlin, 1986). Gratifications that people receive from talk radio include interaction with others, reinforcement of beliefs, and information gain (Surlin, 1986).

\section{Gratifications Sought and Gratifications Obtained}

For gratifications researchers, two distinct types of gratifications are key: gratifications sought and gratifications obtained (Katz, et al., 1973 as cited in Palmgreen \& Rayburn, 1979). Gratifications sought are "expectations about content formed in advance of exposure" while gratifications obtained are "satisfactions subsequently secured from consumption of it" (ibid, 157). For example, an individual may want to listen to "News at Noon" on a radio station in order to stay informed about his or her local community (gratification sought) and after listening they come away with 
information about a new local business that is being constructed (gratification obtained). In this example, the individual's prior expectations of learning about the community are fulfilled and obtained by the broadcast. The distinction between gratifications sought and gratifications obtained is necessary for the study of why people use media because what one seeks from media is not always what one obtains and when an audience member seeks but does not obtain, the chance of that individual using the medium again decreases (McGuire, 1974).

This is an all-too-real threat for rural radio stations, as newer forms of telecommunications have become more prevalent in smaller communities and are starting to displace older, more established channels. I will continue this discussion in the section discussing niche theory.

\section{Uses and Gratifications and Radio}

In its early days, radio was seen as a force for social advancement (creating a unifying American national identity) by connecting the rural with the urban areas (Hilmes, 1999). Radio was helpful in assimilation (for example, The Rise of the Goldbergs dealt with Jewish immigrants assimilating into their new American surroundings); providing entertainment once out of the reach of many individuals (for example opera); and helping provide up-to-date information (Hilmes, 1999). In a 1933 study conducted by the President's Research Committee on Social Trends stated:

"Radio tends to promote social leveling. Negroes barred from entering universities can receive instruction from the same institutions by radio; 
residents outside of the larger cities who have never seen an opera house can become familiar with the works of the masters" (Hilmes, 1999, p. 5).

In terms of uses and gratifications, the uses described by Hilmes show the gratifications of surveillance and information (The Rise of the Goldbergs and university style education) and entertainment (opera).

In rural areas radio was an important information source for a once isolated people. Before the introduction of radio, rural farm areas had minimal contact with the rest of society and farmers had to rely on local newspapers for information concerning weather and livestock and grain buyers for the latest prices on cattle and grains (Wik, 1986). These were not always the most reliable sources; livestock and grain buyers could easily cheat farmers by falsifying the livestock and grain prices for the current day by lowering the selling price. Newspapers' information about weather could be out of date due to the delivery to rural parts being slow (Wik, 1986). The introduction of radio by national broadcasters and land grant schools in the 1920s made it so farmers could tune into a station and learn what the next day's weather was going to be and what the current livestock/grain prices were (Wik, 1986; Hillard, 2003). Rural people could also tune into the station and hear music (often country music), religious sermons, and many educational and entertainment programs (Craig, 2009).

Six years after the introduction of radio into rural areas, the USDA's Radio Service division collected personal testimonies from farmers and other rural citizens to discover how rural individuals were using radio (Craig, 2009). One farmer in Alabama wrote that radio "brings the brains of the United States into our homes...keeps the 
children home nights...good literature, read and explained...religious services on Sunday... and information relating to better farming and housekeeping practices" (Craig, 2009, p. 13). Other rural individuals wrote in that they were able to hear the President speak and they could hear opera stars (Craig, 2009). Within uses and gratifications research, these individuals were using radio for information seeking (better farming practices, religious services, listening to the President and understanding literature), relaxation and entertainment (listening to opera and other assorted musical and entertainment programs), and companionship (keeping the kids home at night).

One of the first uses and gratifications studies to examine radio was Herzog's (1944) study of radio serials. She discovered that those who listened to these radio serials were looking for an outlet to obtain certain gratifications such as to release emotions, compensate for gaps or failures in life, and to seek advice about appropriate behavior (as cited in Rubin, 1985, pp. 241-242).

Another important study of uses and gratifications came from Field and Lazarsfeld (1946). Their study entitled The People Look at Radio examined who was listening to radio, why people were listening, and people's overall feelings about radio. Field and Lazarsfeld (1946) reasoned that information seeking and education were of great importance for radio listeners, in particular, obtaining general knowledge information (politics, quiz programs, religion, etc.) and practical information (homemaking and agricultural information). The gratification of information seeking is one that has echoed throughout uses and gratifications research on radio more than any other. 
Houghten-Larsen (1982) found that in 1982 (thirty-six years after Field and Lazersfeld's study) radio was the number one choice among individuals for information about weather, time, and music. It was also ranked second for information on international events, local events, and companionship (Houghten-Larsen, 1982). Houghten-Larsen observed that radio, in general, is seen as an informational medium. Albarran, et al. (2007) corroborated previous research by examining young adult habits of audio devices (AM/FM radios, mp3 players, internet streaming music, etc.). Their research found that young adults primarily used the radio as a source of information (Albarran, et al., 2007).

Radio can also been used as a force for identity management. In Afghanistan, the Voice of Shari'at Radio was used by the Taliban to broadcast information that was relevant to its religious sect (Skuse, 2002). Listeners (who were suspicious of broadcasts due to the propagandist nature of the programs) tuned into the station because it best supported their conservatism, religiosity, and indigenous culture (Skuse, 2002). Although listeners did not trust the station as a news source, they still listened to it because of the pro-Islamic views it espoused concerning anti-profiteering, health, education, and religious teachings (Skuse, 2002). The study showed that the gratification of personal identity is evident in the use of the radio as a way to support ideological beliefs.

In its heyday, radio served many needs: information, entertainment, companionship, relaxation, surveillance, etc. In the present, radio is seen more as an information medium and sometimes as a way to reinforce an identity. In the current media landscape where radio is abundantly available to individuals, the gratifications 
sought and obtained have diminished. In the next section, I will discuss niche theory and why some mediums lose power to gratify audience members.

\section{Niche Theory, the Radio, and the Internet}

The theory of niche, originally conceived of as a biological theory to discuss the introduction of new organisms into an environment, was later adapted to fit the field of communication (Dimmick, Chen, \& Li, 2004). The theory of niche is conceptualized as the situation where a new medium competes with older, more established mediums and niche theory posits that when a new medium enters into an environment, that medium will be in direct competition with existing media for "consumer satisfaction, consumer time, and advertising dollars" (Dimmick, et al., 2004, p. 22; Dimmick, Kline, \& Stafford, 2000). The consequences of a new medium's introduction include partial displacement of an old medium (new medium takes over some of the roles of the old medium) or exclusion (makes the older, established medium obsolete in its roles (Dimmick, et al., 2000). In order for a new medium to replace or partially replace an older medium, two critical conditions must be met: overlap is high (a new medium delivers the same or better quality of programming than the old medium) and the new medium is superior in giving greater gratification opportunities than the old medium (Dimmick, et al., 2000). Although older mediums such as radio have not been completely replaced by the internet, there has been a reduction in the time spent with older mediums and the gratifications consumers seek from them (Santhanam, Mitchell \& Rosensteil, 2012).

Radio has weathered many new media storms to remain one of the most available mediums in the United States: The PEW Research Center reported that $93 \%$ of survey 
respondents over the age of twelve stated that they used or owned an AM/FM radio (Santhanam, et al., 2012). Yet the audience's reliance on radio as an information and entertainment source has increasingly been displaced in urban and rural areas by newer technologies. The PEW Research Center reports that only 22 percent of those surveyed said they "loved" their local AM/FM station (broadband internet was at 46 percent) and that in 2007 , only 20 percent surveyed said that radio had a "big impact" on them with broadband ranking higher (Santhanam, et al., 2012). According to The PEW Research Center, two-thirds of those surveyed stated that they will listen to their radio in an automobile and less frequently outside of it, isolating it to a section of the day where audience members may not focus much attention on the medium or its message (Santhanam, et al., 2012).

Dimmick, Chen, and Li (2004) found that once radio news users spent time with internet news, $22 \%$ of 94 respondents said they used the radio less. Dimmick, et al. (2004) also found that the gratification opportunities (opportunities to fulfill needs) offered by the internet for news were higher than those of radio. Surprisingly, they discovered that the overlap (the similarities between what gratifications are met by each medium) between the internet and radio was small, with those two mediums possibly gratifying more specialized needs (Dimmick, et al., 2002).

The partial displacement of radio was also shown by Albarran, et al. (2007) in their study of young adults listening habits. With the exception of news, gratifications once obtained by young adults through traditional radio have been displaced by personal mp3 players. While radio was out-performing streaming audio services from the internet, 
streaming audio was coming closer to overtaking radio (Albarran, et al., 2007). Young adult users also reported the negatives of traditional radio including "too many commercial interruptions, too little variety in music, and too much industry consolidation so that all stations sound the same" (Albarran, et al., 2007, p. 99). Over 50\% of those surveyed said they did not listen to traditional radio (Albarran, et al., 2007)

Similar to findings by Santhanam, et al. (2012), users reported their main exposure to traditional radio was in the car, further limiting traditional radio's opportunities to gratify needs (Albarran, et al, 2007). But, Santhanam, et al. (2012) report that the use of mobile devices to stream online content in cars has gone up from $6 \%$ in 2010 to $11 \%$ in 2011. Santhanam, et al. (2012) also report a growth in listening to online only radio stations (57\% in 2011) over traditional AM/FM stations with online streams (40\% in 2011).

While the introduction of newer technologies into rural areas has taken longer due to geographic and economic difficulties, the impacts are similar to those suffered by urban radio stations. Craig (2009) writes that in 2007, in part due to the USDA's Rural Development Program (which was created to help give rural areas financial and technical assistance for community growth) $60 \%$ of rural adults used the internet and $31 \%$ had broadband access (USDA Rural Development-About RD, 2013). This improved connectivity in the rural media landscape, along with the growth of Direct Broadcasting from Satellite (64\%) and cable (11\%), has led to a large overlap between what radio and new media offer, resulting in a potential partial displacement in listeners as audience members can get agricultural market prices online, seek out entertainment online or on 
television, and can look up news, sports, and weather online or on the television. This displacement has resulted in many stations switching to talk formats or modeling themselves after urban stations, losing their regional attributes (Craig, 2009).

\section{The Intersect of Niche Theory with Uses and Gratifications}

If multiple mediums are in competition for people's time, then each medium must offer a unique service in order to stay relevant to maintain an audience. Traditional radio has a presence in most individuals' lives, but the use of it has seen a decline with the introduction of new mediums (television, cable television, broadband internet, iPods, smart phones, and satellite radio/HD radio) which fight for audience time. This link between new medium introduction and freedom of choice creates a situation where traditional mediums could become more and more obsolete as they provide a limited array of choices and audience members must conform to the medium's schedule while a newer medium like the internet offers "greater choice, more control over content, or both" (Dimmick, et al., 2004, p.22)

Both niche and uses and gratification theories have been used to explore gratification opportunities of email and telephone, traditional news mediums and the internet, and video as a source of entertainment (Albarran \& Dimmick, 1993; Dimmick,

et al., 2000; Dimmick, et al., 2004; ). Gratification opportunities are defined as the "characteristics of a medium" relating to "time, space and content" (Dimmick, et al., 2004, p.22-23). The internet provides users many opportunities to gratify needs by offering a variety of content to choose from, and users are able to set their own schedules. Traditional radio, on the other hand, offers less gratification opportunities because of its 
rigid scheduling of programs and lack of listener choice in programming. These opportunities for radio put it at a disadvantage over the internet but radio still has a niche as an information source, and specifically, a local information source:

"While we can go online to read French and Italian newspapers and read blog after blog of pontificators, we still cannot go online to find fresh and well researched journalism on Decatur, Illinois, or Springfield, Massachusetts, or thousands of other communities" (Hilliard \& Keith, 2005, xi).

Traditional radio has an advantage over the internet in that while there is overlap, it is small, resulting in only partial displacement (Dimmick, et al., 2004).

Few studies explore the link between uses and gratifications and niche theory with an emphasis on gratifications sought and gratifications obtained. One goal of the current study will be to explore what needs the radio station either does or does not fulfill for individuals in a community that has increased access to high-speed internet.

\section{News and Program Production}

The current research project explores the gratifications sought and obtained by a local audience from a local radio station. An important aspect rarely discussed, however, is the media producers' point of view. For example, when a producer decides what types of programs to air or news to produce, what goes into that decision? In 1979, Herbert Gans investigated newspapers and found that stories needed to be either interesting or important (or both) to be considered publishable. Hood (2007), citing The Missouri Group, explained that a news story needed to be relevant, useful, and interesting. Within 
those groups, journalists need to look for what Brooks, Kennedy, Moen, and Ranly (2002) describe as "newsworthiness: impact, conflict, novelty, prominence, proximity, and timeliness" (as cited in Hood, 2007, p.6).

In her study of Marketplace, a National Public Radio news show, Usher (2012) found that the structures within the organization influence news and program production. "Deep structures" in the organization included time limits for creating stories, taking into account audience demands, decision making hierarchy, beat pressure" (Usher, 2012, pp. 5-6). Marketplace was also affected by another set of structures stemming from an ideological stance named "Marketplacey": the guiding principles that define the organizational identity and story selection (Usher, 2012). These guiding principles help define and give meaning to the organization and work to create a program that fits the needs of the audience.

One problem that local radio stations continue to face with news production and programming is the outsourcing of programs and news stories to regional offices. Huntemann (1999) elaborated on the repercussions of this phenomenon:

"Without local news staffs devoted to reporting small-town issues as well as national briefs, audiences received canned regional news that may only occasionally cover issues reflecting the listeners immediate geographical area....With a larger area to cover, regional staffs cannot be in touch with community happenings, do not have time to interview local citizens, or cannot devote in-depth coverage to local news events" (p. 403). 
Hood (2007), in his examination of "Centerville" and its local radio station "KWAT," noticed that stories created by local news staffs typically offered more context whereas remotely produced stories (news created outside of the community) were typically surface level examinations focusing on conflict or the potential for conflict. As Huntemann (1999) described, regional or remote bureaus do not have the time to provide in-depth reporting, resulting in news that skirts the surface of an issue and ultimately does not provide enough information for residents.

The production of media, be it news stories or programs, relies on both organizational structures and guidelines that help govern what types of programming or stories will appear on the air and the guidelines for creating said programs or stories. For locally produced material, those in charge of production tend to understand their community and its needs, whereas programs and news stories created remotely lack that background knowledge of an area. For this study, examining the production side at KMMR using uses and gratifications theory will help yield an understanding of the organizational structure that creates local news stories and programs but also features syndicated programs with to the local community. I will explore what choices go into a daily broadcast and what needs the producers hope their programs are fulfilling within their community.

\section{Research Questions}

In summary, uses and gratifications theory examines the audience as active members in their own media choices. Scholars of uses and gratifications are interested in 
what users of media seek and/or obtain. For the current study, I present two research questions which address audience motivations for media selection:

Research question 1: What types of personal gratifications do audience members seek from their local radio station?

Research question 2: What types of personal gratifications do audience members obtain from their local radio station?

Niche theory suggests a displacement effect can occur when media services overlap and compete for audience time. Due to this potential displacement effect, I ask my third research question:

Research question 3: In what ways do audience members of a local radio station report that availability of the Internet has affected their personal types of gratifications sought and obtained?

Although uses and gratifications research often examines the audience side of media, I am also interested in the perceived gratifications that the production side hopes its programming fulfills. It is important to understand how the production side understands its audience so that it can produce programming to fit community needs. I ask two questions that examine the production side of broadcasting:

Research question 4: What types of gratifications do producers at a local radio station perceive the station fulfills within the listening community? 
Research question 5: In what ways do producers at a local radio station perceive the availability of the Internet has affected the types of gratifications sought and obtained among listeners? 


\section{Chapter III}

\section{Methodology}

\section{Introduction}

The purpose of this study is to examine what gratifications audience members in Malta seek and obtain from their local radio station after the introduction of high-speed internet. The study also examined how the producers at KMMR see their programs fulfilling needs within a community. This study employed a micro level research into the perspectives of the individuals who consume media and the individuals who produce media, and through these perspectives help offer insight into the macro level dimensions that comprise Malta and the organizational structure of KMMR. This study employed a qualitative research method to answer the five research questions discussed in the previous chapter.

This chapter is divided into six sections. Section one describes the key constructs comprising this study. Section two describes the operationalizations of perceived gratifications, gratifications sought, gratifications obtained, and internet impact. Section three explains the use of qualitative methods in the current study. Section four discusses the design of the current research, focusing on the sampling procedures and the instruments used in data gathering (questionnaire design and observation). Section five provides an overview on the data collection procedures (contacting audience members and producers and methods for administering questions). Section six describes the data analysis. 


\section{Key Constructs}

The literature on uses and gratifications is crucial to the current study; with this in mind, I used the following definitions described in the literature. Uses mean that individuals are selecting certain mediums or content in order to fulfill their needs (Katz, et al., 1973). Gratifications are the needs fulfilled through media (Katz, et al., 1973). For example, an individual may listen to the radio in order to gain information about his or her local community. In this case, the individual is hoping to gratify a need for information and using the radio as the conduit through which to gratify that need. Within gratifications, I will be examining three aspects. Gratifications sought are defined as "expectations about content formed in advance of exposure" (Palmgreen \& Rayburn, 1979, p.157). Gratifications sought are the gratification expectations of an audience member before he or she engages with a medium and its programming. For example, an individual may report that he or she wants to learn about local activities (informationseeking) so he or she will turn on the local radio station. Gratifications obtained are defined as "satisfactions subsequently secured from consumption of it" (Palmgreen \& Rayburn, 1979, p.157). Gratifications obtained, on the other hand, are what the audience member has received from engaging with a medium. For example, an individual who listened to the "News at Noon" on the radio might take away that a new community garden is opening up in his or her town.

For this study, I have created a third type of gratification: perceived gratifications. Perceived gratifications are the perceptions that producers have concerning what gratification types their programming fulfills in their audience. Perceived gratifications 
are assumptions that media producers have towards what their programming can gratify for audience members.

Along with uses and gratifications theory, literature on niche theory informed the current study. Niche refers to the specialized role that a medium has in fulfilling gratifications. In the literature of niche theory, mediums are in competition with each other for "consumer satisfaction, consumer time, and advertising dollars" (Dimmick, et al., 2004, p.22). Exclusion, also known as displacement, means that audience members are replacing one medium with another medium [for example, replacing radio with television (Dimmick, et al., 2004).] Competitive displacement, also known as partial displacement, refers to a lessening of one medium for certain gratifications in favor of another medium (Dimmick, et al., 2004). In a competitive displacement, the older medium is still used, but to a lesser degree. For displacement to occur, overlap and superiority must be high. Overlap is defined in the literature as the ability for a new medium to fulfill the same gratifications as the older medium (Dimmick, et al., 2004). Superiority is defined as the ability for a medium to provide gratification opportunities for an audience over another medium (Dimmick, et al., 2000).

The production side or producers in this study are defined as individuals who are journalists, editors, disc jockeys and owners who oversee the daily operations at a local radio station. In this study, producers refer to those individuals who work to create, schedule, or air programming for a local radio station. Audience members are defined as individuals who actively seek out a medium and its content.

\section{Measurements}


Below I show how interview questions were worded to elicit responses from interviewees to address the research questions.

\section{Gratifications Sought and Gratifications Obtained}

To answer Research Question 1 "What types of personal gratifications do community members seek from a local radio station?” I asked three questions that examined expectations about the medium and its content.

The first question was, "With the abundance of media choices in Malta (cable/satellite television, newspapers, internet, mp3 players), why do you listen to KMMR?" This question was designed to have interviewees describe in their own words the expectation they have about listening to KMMR. The question is designed in order to elicit general responses from participants which will be probed later to find out specifically what gratifications are obtained by listening to KMMR.

The second question was, "Why do you choose KMMR over other media choices?" This question is designed to show how expected gratifications of KMMR differ from other media sources, thereby helping to create an understanding of what people expect from KMMR compared to other mediums.

The third question was, "How do you personally feel about the programs that are broadcasted on KMMR?" With this question, I am looking at respondents to provide their general perspective on KMMR's programming. By asking this question, I hope that interviewees will tell how they perceive KMMR's programming as a source of gratification fulfillment for themselves and within the community. 
In order to answer Research Question 2 "What types of personal gratifications do community members obtain from a local radio station?" I operationalized gratifications obtained through a series of questions which looked at the specific nature of community members' listening habits and the gratifications they fulfilled from KMMR.

The first question was, "What local programs do you listen to on KMMR and why?" This question was designed to elicit responses from participants about the locally produced programs they listen to on KMMR and the types of gratifications they fulfill. Local programming is important because these programs are created with community members' interests in mind. They include information which may only be accessed through interpersonal communication or through the weekly newspaper.

The second question was, "What syndicated programs do you listen to and why?" This question addressed the programs which are produced in outside markets but are broadcasted on KMMR and what audience members gratify by listening to them. These programs have a different focus from local programming because they are created for a wider, sometimes national audience so they provide less local-centric information but still offer opportunities for residents to gratify needs.

\section{Perceived Gratifications}

Perceived gratifications was investigated using questions pertaining to how the producers see their medium fulfilling gratifications in Malta, Montana. I have operationalized perceived gratifications with six questions for the owners of KMMR and five questions for the disc jockeys in order to answer Research Question 4 "What types of 
gratifications do producers at a local radio station perceive their station as fulfilling within their local community?"

The owners were asked the following six questions. The first question was, "Malta residents have multiple sources for information and entertainment (television, newspapers, the internet, out of town radio stations, etc.), why do you think community members listen to KMMR?" This is a warm up question designed to get the producers to think about why community members listen to their radio station. I am leading off with this question because it will provide a basic understanding of what gratifications KMMR fulfills within the community and from it, I will be able to probe into the specific instances of gratification fulfillment.

The second question was, "Describe the local programming you create. What are your motivations for creating this program? Why do audience members listen to those programs?" With this question, I examined the programs that KMMR creates. The question was composed of two parts, the first part examines the reasoning behind broadcasting these programs and the second question looks at the perceived gratifications that the producers feel the programs fulfill. This helped to provide specific instances of perceived gratification fulfillment.

The third question was, "Describe the most popular nationally syndicated programs you air. What are your motivations for choosing those programs? Why do you believe audience members listen to those programs?" Similar to question number three, except this question explored the syndicated programming that KMMR airs. This question was broken into two questions as well. The first question was looking for the 
reasoning behind the producers choosing these specific syndicated programs and the second question was looking at what they perceive community members are gratifying from the programs.

The other production group I interviewed for this project were disc jockeys. Disc jockeys were asked the following five questions. Question 1 remained the same for disc jockeys and owners.

The second question was, "Describe the local programs you broadcast. Why do you believe community members listen to these programs?" With this question, I was looking at how disc jockeys perceive local programming fulfilling gratifications within the community. Unlike the owners who create the programs, disc jockeys are the ones who air the programs so they have the possibility of bringing a different perspective on what the programs offer the community and what community members take from them since they field calls from the public. The question was used to elicit responses as to what perceived gratifications are fulfilled by local programming.

The third question was, "Describe the most popular syndicated programs you broadcast and why do you believe community members listen these programs?" This question was examining how disc jockeys perceived the gratification fulfillment of syndicated programming. Syndicated programs are not created with Malta citizens in mind, but instead are selected by the owners. This question examined the programs perceived as the most popular by the disc jockeys and the needs they fulfill within the community. 


\section{Internet Impact}

Internet impact was conceptualized as the lessening reliance of gratification fulfillment by one medium due to the introduction of the internet into a community. Specifically, internet impact was examined by looking at the producers' perspective on how their audience is using their station and the internet and the audience members' admissions about replacing KMMR as gratification source in favor of high-speed internet.

Internet impact was operationalized for the producers in the interview guide through two questions to answer Research Question 5: "In what ways do producers at a local radio station perceive the availability of the Internet has affected the types of gratifications obtained within their listening community?"

The first question was, "In your opinion, how has access to high-speed internet impacted listenership?" With this question, was looking to see how the producers perceived the internet has impacted listenership in general. By asking this, I was hoping that the answers given would provide clarity about if the internet has created a displacement effect on use of KMMR. I was also hoping that interviewees would discuss the characteristics of the internet and radio in relation to niche theory (superiority and overlap).

The second question was, "In your opinion, what do you perceive to be the long term effects of high-speed internet on your listening audience's use of KMMR?" By asking the producers this question, I was interested in discovering how the producers perceived the continued use of high-speed internet and the potential effects it had for 
people's use of KMMR. This question was designed to get the interviewee to think about potential displacement effects.

Internet impact for the audience members was operationalized in the interview guide with two questions to answer Research Question 3, "In what ways has the availability of the Internet impacted community members' perceived use of their local radio station for fulfilling gratifications?"

The first question was, "How would you describe your internet usage?" This question was designed in order to get a general understanding of respondents' internet usage. By asking this question, I was hoping that interviewees would describe specific gratifications they fulfilled by using the internet. This question led into my second question on possible displacement effects.

The second question was, "Can you think of times that you used the internet for something you could have gotten from KMMR?" This question was designed to elicit from respondents specific instances of what gratifications they fulfilled through the internet that they used to fulfill through the radio station. This question was created to provide insight into the relationship between audience member use of KMMR and the internet and if any displacement has occurred and why.

\section{Qualitative Methods}

The study employed a qualitative research methodology. The purpose of qualitative research is to uncover an in-depth understanding of populations by allowing individuals who comprise a population to express their experiences in their own terms; thus creating a personal narrative that cannot be captured through quantitative means 
(Berg, 1989; Lindlof, 1991). Qualitative research comprises four characteristics which are important for this study: qualitative research has a "theoretical interest in human interpretational processes", it is "concerned with the study of socially situated human action and artifacts", it uses "human investigators as the primary research instruments", and it relies "primarily on narrative forms for coding data and writing the texts to be presented to audiences" (Lindlof, 1995, p. 22). In this project, I am interested in a rural community's relationship with a local media institution as witnessed by local residents. The study was expressly interested in the socially situated actions involved in the production of a local radio station and the reasons why community members choose a particular medium to gratify their needs. This study relied on the author as a primary investigator who lived in a rural environment for three weeks interviewing individuals and observing radio station operations. Finally, the coding of the data relied on interviewees' narratives and the presentation of the research will provide a narrative from both the producers and the consumers of KMMR.

Qualitative methods were deemed appropriate for this study for the following reasons. First, the purpose of this study was to discover the unique experiences held by the production team at KMMR and the personal (and potentially unique) gratifications audience members receive from KMMR. Lindlof (1995) explains that quantitative research transforms data into mathematical numbers for generalizability about a larger population; potentially resulting in the rich, interpretive meaning behind participants' answers to be lost. A qualitative study allows more freedom for participants and researchers to create and explore different ideas in interview or observational settings. In 
the current study, while a quantitative approach would have sufficed, it would have lessened the opportunities for discussion of personal connections both community members and producers feel towards their local station and its programming.

The second reason for choosing qualitative methods was that the researcher is not attempting to produce a work that offers prediction and generalizability. "The kinds of explanations we seek in qualitative research are almost exclusively ones of understanding, not prediction or control" (Lindlof, 1995, p. 56). Qualitative research offers insight into "individual families, subcultures, organizations, communities, or individuals" which can be generalized to similar cases (p. 57). In this study, the researcher is interested in understanding a rural community's radio station from the operations side and the consumption side. Findings from this research could be helpful in creating an understanding of how producers of radio in other rural communities create programming and how community members in other rural communities interact with an established medium while interacting with a new medium.

For this study, I chose to perform a case study to gain an in-depth understanding of the changing media environment in a rural community. Case studies are effective when researchers want to answer "how" questions, rather than "why" questions and help create context for phenomena (Baxter \& Jack, 2008). For this study, I was interested in understanding how the introduction of a new medium into Malta had potenitally affected audience members' use of KMMR. Alhough this could have been done through survey research, having context for audience member use provides insight into their lives and media choices, and also the role that KMMR plays within the community. 
The purpose of this study was to examine production and consumption of mass communication and the effect that high speed internet has had on an audience's use in a rural environment. For the reasons listed above, I believe that a qualitative approach would yield the type of in-depth understanding that would offer insight into a new era of mass communication for a rural area.

\section{Research Design}

\section{Sampling Procedures}

Population. For the purpose of this study, the population was composed of current residents of Malta, Montana. From the population, I drew two samples consisting of KMMR's audience members and another of those who work at the station.

Sample Type and Size. The current study employed a snowball and quota sampling technique with the help of personal relationships I have with the owners of KMMR and informants within the community.

The production side (or producers) at KMMR were individuals who own, work at KMMR, schedule programming, perform on-air duties, write news or sports stories, and/or create locally oriented programs for KMMR, including the owners of the station and disc jockeys. The owners of KMMR are individuals who own and run KMMR Inc. and are in charge of programming and management. Disc jockeys refer to individuals who perform on-air duties including, but not limited to, announcing: weather reports, sports reports, news reports, and upcoming or previously aired songs; selecting music; and taking musical requests from listeners. The producers of KMMR needed to meet the following requirements: a) must own or work at KMMR as either an owner or a disc 
jockey, b) must be over the age of 18 , and c) must live in Malta, Montana. The researcher interviewed the two owners of KMMR and two full time disc jockeys making a total of four production side participants. I chose these four individuals to interview as they are the "elites" at KMMR, individuals who can provide the insider story and perspective on the inner workings of KMMR (Feldman, 1981, p.35). I chose the owners to interview because they are in charge of programming for the station and I wanted to discover why they have selected particular programs for air and what they see these programs fulfilling within the community. I also selected two disc jockeys, one morning and one afternoon disc jockey, because they are the disc jockeys who spend more time in the station and have worked at the station longer than the evening disc jockeys. Also, the morning and afternoon disc jockeys play a variety of programs along with music while the night-time disc jockeys generally only play music or a sports game during high school football and basketball season. Being able to have respondents who were versed in the variety of programming offered by KMMR provided an opportunity to discover what the programming offers the community.

The sample of four members on the production side was comparable to Hilgenberg's 2010 research where she contacted eight disc jockeys and directors at the Minnesota Public Radio Station 89.3 The Current in St. Paul, Minnesota, but was only able to interview four disc jockeys on their perceptions of local identity transmitted by the station. Hilgenberg argued that the interviews in general, and her interviews of the production side at the station, allowed researchers the opportunity to peer inside the inner-workings of a radio station and to understand how those within the station perceive 
what it is they are offering the community. Hood (2010) had a similar sized sample in his study on "KWAT" (the pseudonym given to the station) in "Centerville" (the pseudonym given to a Midwest city). His sample was comprised of four news writers and one news director. Hood (2010) noted that these interviews "allowed for a richer understanding" of "KWATT" (p.159). The sample size of four producers for the current study provided the same opportunity for insider information into the inner-workings of KMMR and the perceptions on what KMMR provides the community.

The second sample I drew for the current study were the audience members. Audience members needed to meet the following requirements: a) must be over the age of eighteen and b) must have established residency (mailing address to a house or an apartment). For the current study, I used the nonrandom sampling technique of snowball sampling and quota sampling. Snowball sampling utilizes informants as a source of subject recruitment by having a participant list the names of potential subjects who are active members of the community under study (Lindlof, 1995). Through the use of informants, I had access to a knowledgeable sample of individuals who are active listeners of KMMR.

The second sampling procedure I utilized was quota sampling. In quota sampling, a researcher has a pre-specified list of characteristics which are used to guide subject recruitment (Babbie, 2007). The use of quota sampling is beneficial as it allows a researcher to gather participants who are representative of a community (Babbie, 2007). For this project, I devised age cohorts (30-39, 40-49, 50-59, 60 plus) and an equal distribution of both males and females (two males and two females for each cohort) for 
each group based on the characteristics of the listening audience (ages 30-60 with an equal distribution of males and females) as specified by one of KMMR's owners (C. Kielb, personal communication, April 25, 2013). I created age cohorts for this project to understand why each age group used KMMR and if similar gratifications were reported between the age groups. I chose a sample of two males and two females for each group in an attempt to create equal gender representation. A sample of four individuals per age group, with one hour interviews per person, provided me with rich detail as to how members of the listening audience use KMMR in their daily lives. While this sample was not large enough to make generalizable claims about each age cohort and sex, it offered insight into the experiences that audience members have with KMMR.

\section{Contacting Producers and Residents}

After receiving permission from the Portland State University Human Subjects Research Review Committee to conduct this research, I contacted the owners of KMMR by telephone, confirmed their willingness to participate in the current study, and informed them that their participation in the study was voluntary. Once they agreed to participate in the study, I discussed with them an appropriate date to travel to Malta and scheduled dates to interview and observe them in the KMMR office. I interviewed each owner separately. Before interviewing, I presented the informed consent release to each owner and had them complete it. I sought permission from each owner to tape record the interviews and to use their legal name in the study. Each owner was informed that they had the right to withdraw from the study at any time. 
I sought permission from the owners to interview two disc jockeys and to observe them during their shifts. Once permission from the owners was granted, I asked permission of the disc jockeys to interview them and shadow them. I informed them that their participation was voluntary. I scheduled one day with each disc jockey for an interview and informed them that the interview would be tape recorded. Before interviewing, I sought informed consent from each of the disc jockeys. Disc jockeys were notified that their responses were confidential and unless granted, they would be assigned a pseudonym and their shift times would not be divulged.

The final sample of this study was the residents of Malta, Montana. Contacting residents involved the use of my personal knowledge of the town and the use of informants within the community to help select residents who would fulfill the sample guidelines outlined above. Informants in this study were family friends and people I had a personal relationship with. I described to the informant the purpose of my study and asked them if they had any knowledge of individuals who would be good to interview. Once an informant had informed me of a potential participant to interview, I would call the potential participant and tell them that I was performing a study on the use of KMMR by local residents. I informed them that participation was voluntary. I scheduled an appointment at the participant's convenience to review and complete the informed consent and perform an interview. I sought permission from each participant to allow the tape recording of each interview. Each participant was informed that their participation in this study was confidential and that identifying information would be minimal in the study and would include age, sex, general occupation (ie. farmer, business owner, 
clergyman, postal worker, mechanic, teacher, convenience store clerk, stay at home parent, etc.), and if they live within the town or located out in the countryside. I informed each participant that no other identifying information would be present within the transcripts or the finished study. I told them that I would be giving them pseudonyms in the study. I informed each participant that I was including this minimal identifying information as it may offer different perspectives on how different individuals use KMMR. Finally, each resident was informed that they had the right to withdraw from the study at any time.

\section{Data Gathering Instruments}

Protocol Guide Interviews were conducted with each participant. Interview guides were developed by me under the guidance of my advisers consisting of openended questions designed to elicit specific responses from individuals who participated in either the production side or the consumption side of KMMR's programming. I chose interview as a data collection technique because it allows the researcher to "learn about things that cannot be observed directly by other means" and allows the researcher to verify, validate, or comment on data obtained from other sources (from other interviewees but also from the literature (Lindlof, 1995, p.166)

Interview guides concerning the production side of broadcasting were created for the owners of KMMR and the disc jockeys. Questions asked to the owners focused on why they chose their current programming schedule, the reasons behind those choices, what needs they thought their programming gratified in the community, and how they felt the of the growth of high-speed internet into the area had impacted listeners' use of 
KMMR to gratify needs (Research Question 4 and Research Question 5(Appendix A)). Questions asked to the disc jockeys focused on their views about what needs are gratified in the community through KMMR's programming and how they saw the growth of highspeed internet into the area impacting listeners' use of the radio to gratify needs (Research Question 4 and Research Question 5 (Appendix B).

Interview guides for residents of Malta focused on their views about what role they see KMMR playing within the community, the gratifications they seek from the KMMR, gratifications they obtain by listening to KMMR, and how they perceive highspeed internet has impacted their gratification seeking and obtaining from KMMR (Research Question 1, Research Question 2, and Research Question 3 (Appendix C).

\section{Individual Interviews}

Producers Individual interviews were conducted in Malta, Montana in the summer of 2013. I interviewed the producers of KMMR. Interviews of each producer $(\mathrm{N}=4)$ occurred once and ranged from forty minutes to two hours. Interviews involved talking to one participant at a time. To preserve privacy and facilitate in-depth conversation, each participant chose the time and location of the interview. (See Appendix D and Appendix E for producer recruitment scripts.)

At the beginning of the interview, I informed the participant that I was a graduate student at Portland State University and that I was conducting research for my Master's thesis. I explained my study by saying that I was interested in the production and consumption of a rural radio station's programming, the gratifications it fulfills within a community, and the potential impacts of internet access on listenership. I explained that 
the findings would be helpful to the station because it would highlight specific reasons as to why audience members do or do not listen to KMMR. As compensation for agreeing to participate in the study, I offered the owners a copy of the finished paper. I informed the owners and the disc jockeys that the interview would take approximately one hour to complete. I informed the owners that since they own KMMR Inc. their names cannot be confidential. Disc jockeys were given the choice of whether they wanted their legal names to appear in the study or if they would like anonymity, in which case their legal name and their shift would not appear in the study. Due to the small staff of the station, both disc jockeys had to consent to waiving anonymity in order for their names and shifts to appear in the study. If the disc jockeys did not waive confidentiality, I informed them that their names and any identifying information in the audio tapes and transcripts would remain confidential. I also explained that each interview would be audio recorded and that I would be taking notes on their responses. Further, I explained to them that participation in the study was voluntary and that they had the right to withdraw from the study at any time. I also informed the participants that they may ask for a question to be repeated and they could refuse to answer any questions that made them feel uncomfortable.

Once I explained the study and participant's rights and if they agree to participate in the study, I had them sign an informed consent agreement that outlines the purpose of the study and their rights as participants. I informed each participant that they would receive a copy of their informed consent (See Appendix F and Appendix G for station owner and disc jockey informed consent forms). 
I started each interview with background questions about the station and each producer's role at the station. After that, I asked each participant questions regarding perceived uses and gratifications of KMMR, and end with questions about the impact of high-speed internet.

\section{Audience Member Interviews}

I did a second wave of interviews, with residents of Malta who listened to KMMR $(\mathrm{N}=17)$. I gathered a list of potential participants in the study with the assistance of two informants within the community. I chose to use informants because they act as guides to help researchers locate information important to a study (Babbie, 2007). The informants I used were individuals whom my family or I had personal relationships with in the past and whom I knew would provide in-depth information about personal use of KMMR. Before I met with an interviewee, an informant contacted the potential participant by phone. They asked each participant if they remembered who William Pinnock was (usually by asking them if they remembered my parents) and asked them if they would like to participate in a research study. I was given the phone and informed them that I am a graduate student at Portland State University and that I am conducting research for my Master's thesis and that I was told by an informant that they would be a good person to talk with about my current research. I explained my study by saying that I am interested in the production and consumption of a rural radio station's programming, the gratifications it fulfills within a community, and the potential impacts of internet access in the community on listenership. I informed participants that the interview would take half to one hour to complete. To protect privacy and facilitate in-depth discussions, 
participants had the choice of when and where to meet for an interview and I promisted not tell anyone if they declined or agreed to participate in the study (See Appendix I for resident informed consent).

At the beginning of each interview, I explained the purpose of the study. I informed them that participation in the study was voluntary and that they could withdraw at any time. I informed the participant that they would be tape recorded. I also explained to the participant that their identity in the audio tapes and the transcription would remain confidential and that I was going to assign them pseudonyms. I informed them that I would be using the minimal identifying information, such as age, general occupation, whether they live in town or out of town, and media usage, in the study. I informed them that they can have me repeat a question at any time and if they feel uncomfortable with a question, they can refuse to answer. I then explained they would not be monetarily compensated, but instead would be given an outlet to voice opinions about a local media institution and that their thoughts could have an impact on KMMR's programming.

Following this, I presented the participant with an informed consent release and asked him or her to read and sign it. I told each participant that they would receive a copy of the informed consent. After this, I turned on the tape recorder, checked levels, and began the interview. I asked each participant to give background knowledge of the town and themselves, I then proceeded to ask them about what they use KMMR for and what KMMR's role is in the community. I finished up by asking them what they use the internet for and how it has (potentially) impacted their listening habits. 


\section{Data Analysis}

Qualitative research focuses on the experiences of individuals. The experiences of those who work and listen to KMMR provides understanding as to what a rural radio station offers its listening audience. In this study, I took an inductive approach in analysis. Lindlof (1995) explains that induction allows "data [to] slowly resolve into concepts and specific research propositions through the investigator's own increasing skill at understanding" (p. 56). Inductive analysis helped to illuminate such gratifications as information, entertainment, companionship, and allowed for themes and concepts to emerge which were not in the manifestations of gratification typologies which I will be employing.

Analysis of the transcribed audio tapes and field notes occurred in several phases. The first phase was the preliminary coding which involved me re-reading transcripts to become reacquainted with them (Lindlof, 1995). Re-reading transcripts and field notes helped me to begin to understand the data I had collected and help me to find themes and concepts that were embedded in the text. The second phase of analysis involved thematic coding. Thematic coding was chosen because the gratifications I am looking for have been documented in previous typologies. The typologies I have chosen are Palmgreen and Rayburn (1979) and Rubin's 1981 typology (as cited in Katz, 2012). In analyzing the transcripts, I coded for wording relating to specific gratifications of information, enjoyment, entertainment, social interaction, companionship, passing time, and excitement. I analyzed the transcripts for gratifications sought ("I listen to KMMR because__ „), gratifications obtained ("I get __ out of KMMR"), and internet impact 
("I use the internet for" and "I use the internet because"). After I had coded the data, I began to create subcategories for each of the gratifications. For example, under “information” I created subcategories such as "agricultural information”, "sports information", "local information", etc based upon the specific types of information that were sought and obtained by listeners. Once I had completed this task, I grouped the different concepts together into a typology of perceived gratifications of producers and the gratifications sought and obtained of rural radio listeners. Once I had created the groupings, I entered the data into an Excel spreadsheet noting each participant's name, age, profession, hours spent with medium, where they listened to the medium, and the gratifications sought and obtained.

The final aspect of the data analysis involved the comparison between the producers and the audience members. Though not explicitly stated as a research question, the comparison of why producers air programs and what gratifications audience members take away from the programs can offer insight into how well the radio station is serving the community. By doing this, the researcher was able to discover any potential disconnects between what the producers feel their station gratifies in the town and the community members' admitted use of KMMR. 


\section{Chapter 4}

\section{Findings}

Interviews were conducted from July 2013 to August 2013 in Malta, Montana. A total of twenty-one participants were interviewed for this study, but one was excluded because he/she did not meet the guidelines.. Four individuals from KMMR radio (the two owners of KMMR Inc. and two disc jockeys) were interviewed about their perceived thoughts of KMMR use. The researcher chose these individuals because they play key roles in the station. These individuals granted the researcher the right to use their legal names. The other sixteen participants were given pseudonyms in order to protect their identities.

Once the data collection and transcription phase was complete, I discovered that the interviews with the producers at KMMR failed to answer Research Question Four, "What types of gratifications do producers at a local radio station perceive their station fulfills within their listening community?" and Research Question Five, "In what ways do producers at a local radio station perceive the availability of the Internet has affected the types of gratifications sought and obtained within their listening community?" Despite probing questions, the interviewers gave only cursory responses to the questions asked. I decided against including the two research questions in the analysis.

Sixteen residents of Malta were interviewed regarding their use of KMMR. These participants were broken into four age groups: 28 to 39,40 to 49,50 to 59 , and $60^{1}$ plus. I

1Difficulty in finding a fourth participant in the 30 to 39 age range resulted in me choosing a 28 year old individual. 
chose individuals in these age groups because the listening audience of KMMR was described to me to be between 30 and 60 and older by co-owner Claudette Kielb. I put four participants into each age group so no one age group would be overrepresented. I also recruited participants from a variety of occupations and backgrounds. Due to the study consisting of non-probability sampling techniques, I recruited from various ages, occupations, and backgrounds in order to get a breadth of different perspectives from residents and their experiences with KMMR and the internet (Babbie, 2013). I interviewed one clergy member, three business owners, one part-time worker, one insurance agent, one banker, one teacher/rancher, one rancher/farmer, one natural gas truck-driver/rancher, one retired teacher, one human resource worker, one individual involved in community and economic planning, one agricultural educator/farmer, one attorney, and one police officer. Participants were chosen through the use of snowball and quota sampling. I used two informants within the community to assist me in choosing participants based on the sample characteristics I had created.

\section{Participant Biographies}

Following are short biographies of each of the participants.

"Erik Torrance",2 (64 years old) is a local business owner in Malta. Erik moved to Malta in 1994 and eventually took over the business where he had been working at. Erik likes to listen to KMMR every day while he is in the office or driving in his vehicle so he can hear local information, make sure that his ads are being read correctly, and to hear

2 In order to protect the identities of the participants, I given each participant a unique pseudonym. Unless stated otherwise, the names that appear in this study have been created by me. 
music. While he does not listen often in the morning he said that, "In the mornings when they have a radio-thon going on for trying to raise money for something, I will always tune in and listen and make my pledge." Most days Erik does not listen to KMMR at home and will instead watch television.

Police Officer Garret Dunne (40 years old) was born in Malta and, with the exception of a few years he spent away from Malta, has lived in here for thirty-seven years. For Garrett, KMMR is not a significant part of his life. Garrett listens two or three times a week for ten to fifteen minutes in his car while he is driving to work so he can catch up on local information. Garrett said the only other time he listens is when he is checking up on a news story that he sent to KMMR to make sure that they are reading it correctly.

Veronica Matisse (36 years old) is the owner of a local cafe and part-time rancher. Veronica has spent most of her life in Malta. According to Veronica, she may listen to KMMR for about ten minutes a day in her vehicle, unless there is a sporting event, she often turns on her satellite radio while she is cooking at the cafe. She explains that this is due to the metal roof which causes poor reception of KMMR.

Greg McNulty (32 years old) is a local insurance salesman. Greg moved to Malta from a larger Montana city. Greg's listening habits to KMMR vary by season: during the sports season, he will try to tune in more often to catch sporting events and sports news, but during the non-sports season, he will listen less often, typically in his vehicle so he can stay informed about the community. 
Natural gas truck-driver and rancher Robert Derringer (44 years old) grew up on a farm 65 miles outside of Malta and has lived in Malta for thirteen years. Robert spends most of his day driving truck which is where he has his highest exposure to KMMR. Robert listens to KMMR five to six times a week for three to five hours a day. As a truck driver, he is interested in finding out the weather conditions for the day and, as a rancher, he is interested in finding out the price of cattle.

Graham Purks (55 years old) is a pastor in Malta. Graham moved to Malta from another small Montana community. For Graham, KMMR is an important tool in his dayto-day life, and has also helped him understand the community of Malta. By hearing local names on the radio he was able to know who was who in the community. Graham listens to KMMR every day for one to three hours at his home and in his vehicle. He tunes into KMMR for local information on KMMR and for country music and classic rock oldies.

Chris Droser (55 years old) is a Malta attorney. Chris was raised in a small Montana community. He attended college in Montana for his Bachelor's degree and then pursued a law degree. After graduating, Chris moved to Malta with his wife to work as an attorney and raise a family. For Chris, KMMR is an integral part of his day. He wakes up with it Monday through Friday and listens from 7 a.m. to 5 p.m. In that time, he listens for information that is specific to Malta and his work.

Local teacher Leslie Kilgore (55 years old) moved to Malta to pursue a teaching position in the local school system. In addition, Leslie is also a rancher. She and her husband's ranch is located sixty-three miles from Malta. She does not listen to KMMR at the ranch home because of poor reception, but does listen when driving to Malta or 
around Malta. During the week, Leslie listens to KMMR at least two hours a day, starting at 6:30 a.m. when she is driving to work. Leslie explained that she likes to listen to KMMR because it keeps her informed about what is going on in town before she arrives and she enjoys the music selection.

Kaleigh Strandberg (28 years old) has lived in Malta for five years. She first came to Malta when she was working with a non-profit organization. She holds a position in Malta that involves community and economic development. Kaleigh listens to KMMR Monday through Friday at her office, but rarely listens away from work. She explained that since she hears KMMR all day, she does not need to listen outside of work. Kaleigh's listening habits tend to be passive since the radio is on all day at work and it becomes part of the background. She does actively listen for certain local information important for her job or listens for an event she may want to attend. She also listens to make sure her advertisements are being played.

Rita Hoener (63 years old) moved to Malta for her husband's job. After settling in Malta, Rita started as a substitute teacher in the public school system and later became a full-time teacher. Now retired, Rita and her husband travel occasionally and spend their winters in Arizona. Since retiring from teaching, Rita said that her listening habits have decreased but she still wakes up to KMMR every day on her radio alarm. She listens to KMMR in her vehicle, when she is working in her downstairs room, when she is at the family cabin, and on the internet in Arizona. When asked why she listens to KMMR, Rita said that she likes the music, likes the people on the radio, and it gives her local news and information. 
Lauren Bergstrom (35 years old) has lived in Malta for ten years. Lauren grew up on the west coast and moved to Malta with her husband. Upon moving to Malta, Lauren started working at a locally owned bank. According to Lauren, she listens to KMMR for an hour a day. Lauren likes to listen to KMMR in her car, occasionally at home, and occasionally at work where it is on in the back office. She actively listens to KMMR for sporting events, radio-thons or radio auctions. She also likes to listen to KMMR for the music, to find out local information, to listen for the bank's advertisements, and to find out what deals the local stores are offering.

Local business owner Roberta Glass (66 years old) has lived in Malta for thirtyeight years. Roberta is originally from a small town located outside of Malta. She moved to Malta to marry her husband and later they opened their business. Roberta listens to KMMR every morning at her home. She also listens in her vehicle because that is the only station her car radio receives. She does not listen at work because the metal roof of the building blocks the radio signals. Roberta likes to listen to KMMR for music, the news, and the morning religious segment. During the sports season she likes to listen to the playoff and tournament games. She also likes to use the radio as a companion for her cat so that he does not feel alone when no one is in the house.

Todd Fogarty (46 years old) moved to Malta in 1999 with his wife and children. Raised in a rural eastern Montana community, Todd moved to Malta to work as an agricultural educator to help educate the farmers in Phillips County about the latest farming information; Todd is also a farmer. Todd listens to KMMR every day for seven hours, starting at his home where he wakes up to it and then in the office where it is 
already turned on. He listens to KMMR to find out about weather, agricultural information, world news updates, and Montana-centered news.

Jeffrey Coleman (60 years old) has lived in Malta his entire life. Jeffrey currently works part time at two local businesses. When he is not working, Jeffrey enjoys weather spotting, talking with people in the community, playing with his cats, and spending time outdoors. Jeffrey listens to KMMR every morning and afternoon in his car. He listens for weather reports, local news items, music, and local sports news. For Jeffrey, KMMR is refreshing to listen to. "[It's] just a good wake up call. Getcha to back to small town America, what's goin' on in the community, it enlivens you, it wakes you up." Jeffrey also listens to KMMR because it is pleasant for him. "it's our local station, why would I want to listen to it? It's pleasant, it's comfortable...it's a peaceful radio station, it just kind of kicks you back and you can listen to it and you don't get irritated by it."

Sarah Frank (43 years old) moved to Malta in 1995. Sarah grew up in Montana and went to college at Montana State University where she received a degree in elementary education. She worked at a school in Malta for two years before moving to Great Falls. After two years, she moved back to Malta and got married. She is currently working in human resources at the Malta hospital. For Sarah, listening to KMMR is a seasonal habit: during the school year she listens to keep track of her children's school activities but during the summer she listens occasionally. Sarah said she actively seeks out listening to KMMR once a week when she is driving in her car, but the answers she provided hint that she may listen more. Sarah listens to KMMR for school information concerning lunch menus or changes in the school's scheduling of activities. Sarah's use of 
KMMR for this information is "the beginning of our [family's] day and we can go on and do the rest."

The final participant in this study was the farmer and rancher Russel Lynn (52 years old). Russel has lived in Malta his entire life. Russel lives approximately twenty miles outside of Malta and raises cows and grows hay. KMMR is a big part of Russel's life and he listens every day for approximately six hours in his swather ${ }^{3}$, pickup truck, another truck he uses, or anywhere else there is a radio. He likes to listen so that he can stay informed about local information and weather. A former athlete, Russel listens to sporting events on KMMR if he cannot make it out to a game. He also likes to hear updates on local athletes and to hear the local coaches talk about sports. Russel also listens to the farm and agricultural reports to find out the prices of grain and livestock.

\section{Gratifications Sought}

Research Question 1 asked "What types of personal gratifications do audience members seek from their local radio station?" Gratifications sought are "expectations about content formed in advance of exposure" to a medium ( Katz, et al., 1973 as cited in Palmgreen \& Rayburn, 1979, p.157). In order to answer Research Question 1, I created a series of questions (refer to Chapter 3) that asked participants to describe the reasons why they listen to KMMR. The questions were designed to have the participants give answers which detailed what they expected to hear on KMMR. In the coding process, I adapted a code sheet from a survey created by Palmgreen and Rayburn (1973) which asked

3 A piece of farm equipment used for cutting hay. 
participants about what they were expecting to hear from a particular medium. I coded participants' responses to as gratifications sought if they described what gratifications they were expecting to receive from KMMR.

During the interviews, information and enjoyment were the top gratifications audience members expected to receive from KMMR. Table 1 displays counts of the gratifications sought by audience members: 
Table 1

Gratifications Sought by KMMR Listeners

Gratification Sought $\quad \operatorname{Number}^{\mathrm{a}}(\mathrm{N}=16)$

Information

16

Enjoyment

11

Companionship

2

Excitement

1

Social Interaction

1

Escape

1

${ }^{\mathrm{a}} \mathrm{N}=16$ 
In the remainder of this section, I will be providing specific examples from audience members on the gratifications of information, enjoyment, and companionship.

\section{Information}

All sixteen of the participants stated that information was what they were seeking from KMMR and fourteen participants stated that local information was what they were expecting to hear. I coded utterances as "information" if participants described gaining knowledge for personal or professional reasons. Local information was coded as utterances that described information specific to Malta.

Information seeking was an integral reason for many participants tuning in KMMR. Greg McNulty explained, "I usually listen to stay linked in to what is happening. It is the best way to stay on pace with what is happening locally." Chris Droser agreed by saying:

"I do it [listen to KMMR] because I wanna know what's going on in my community and that's the only place I'm going to get it. You don't get any [information], off of the Great Falls station, you don't hear too much about what's going on in Malta or Phillips County."

Leslie Kilgore added to Greg McNulty and Chris Droser's comments by saying: "I like to hear what's going on in town and you never know what's going on sometimes or really who died, ya know, I know that sounds terrible but, sometimes that's the first means of knowing that somebody has passed away." 
Pastor Graham Purks stated that he listens, "Because I believe I am going to get the information that's gonna help me serve the community and keep me within what's happening within the community." Robert Derringer said he listens to KMMR because, "It keeps me informed about the weather and what's going on around here." Sarah Frank agreed by saying “it's local, so I want to see if there is anything I need to know type of thing."

Fourteen out of the sixteen participants interviewed stated that they were expecting to hear local-centric news and information that is pertinent to their daily lives. A medium that can provide Malta with local specific information is vital for residents as KMMR is one of two main sources for local information and the only daily local information source.

Local information for participants was the most sought-after information gratification; others were: local sports and world news. Local sports information was sought by seven people. Greg McNulty explained he listens to basketball and football games because he was interested in, "how the kids are doing and I have young kids so it's not always possible to go to the games." Veronica Matisse stated that she listens to sports because she, "Just wants to hear how the home team is doing."

Another information gratification sought by participants was world news. Todd Fogarty and Erik Torrance explained they like to listen to KMMR because they will hear world news information from the ABC World News which helps them understand current world events. 


\section{Enjoyment}

Enjoyment was the second most sought-after gratification. I coded utterances for enjoyment if the participant discussed how she or he "liked" or "enjoyed" entertainment aspects of KMMR, such as music, programs, live sporting events, and people on the radio. The most popular way for participants to seek enjoyment gratification was to listen to the music on KMMR. KMMR has two formats: country and western music from 6 a.m. until 6 p.m. followed by classic rock and pop from the 1960s, 1970s, 1980s, and early 1990s in the evening. This format can be found Monday through Thursday on KMMR. Friday through Sunday, country and western music is played until noon and then until closing classic rock and pop is played. This format has come to be popular with the participants interviewed. Robert Derringer explained, "they got good music on there most times...I like more of the country style and they play a lot of the older [music]...it ain't a bunch of rock stuff." Russel Lynn stated, "I like their music...And I like country music so that's why I listen in the day time I guess.” Jeffrey Coleman (who is a fan of classic rock) explained there are two stations that are available for Malta residents to tune in to:

"One of them...they play the hip hop stuff...and I'm not into that, and KMMR plays more of the down home sound, they mix up country, they mix up a little bit of the classic rock, they mix of a little bit of easy listening and stuff like that." 
Erik Torrance said he likes KMMR because he expects to hear the music of his youth, "A lot of oldies and country.... That was the type of music I listened to as a kid and that's the type I still like."

\section{Companionship}

The use of KMMR as a companionship tool was discussed by three participants. Companionship is defined as using a medium as a way to spend time with another person (Rubin, 1982). In the study, I did not find anyone who used the radio as a way to spend time with others, but instead, I found three individuals who discussed that they use the medium as a companion. I coded these utterances as companionship if a participant talked about how having KMMR on was like having company. Rita is a retired school teacher whose husband spends his days at his job, leaving Rita home alone during the morning and afternoon. Rita has many friends in the community but when she is working in her chore-room, she enjoys have an electronic companion that can keep her company. She said she likes to have the voices in the background.

Roberta Glass is another individual who discussed the use of the radio as a companion, but she uses it for her cat. She said, "He's kind of neurotic, I guess is the way to put it. And just so that he, or I think, that he thinks he's not alone."

\section{Gratifications Obtained}

Research Question Two asked: What types of personal gratifications do community members obtain from a local radio station? Unlike a gratification sought, a gratification obtained is what an individual receives from using a particular medium. During my interviews, I found that information, entertainment, and social interaction 
were the top three gratifications obtained from listening to KMMR. I created these categories by coding utterances relating to the type of gratification that was obtained. I obtained these utterances by asking open-ended questions concerning programming that individuals listen to on KMMR and what they get out of those programs.

An interesting finding was that "social interaction" was a much more common gratification obtained than a gratification sought. It would appear that gathering information to discuss with people is not a reason to seek out the radio, but it is an outcome of radio listening. Table 2 shows the gratifications obtained by individuals: 
Table 2

Gratifications Obtained by KMMR Listeners

Gratification Obtained

Number ${ }^{\mathrm{b}}$

Information

16

Enjoyment

14

Social Interaction

12

Excitement

4

Passing Time

2

Companionship

2

${ }^{\mathrm{b}} \mathrm{N}=16$ 
In the rest of this section, I will be discussing the specifics of the gratifications that are obtained from participants.

\section{Information}

Among gratifications obtained, information was the most discussed. Information utterances were coded as knowledge that a person gained for personal or professional reasons from listening to the radio. Table 3 displays the types of information residents obtained from KMMR: 
Table 3

Types of Information KMMR Users Obtained

Information Gratification Obtained $\quad$ Number $^{\mathrm{c}}$

Local Sports Information

12

Community News Information

Business Information

8

Weather Information

7

World News Information

4

State News Information

2

${ }^{\mathrm{c}} \mathrm{N}=16$ 


\section{Local Sports Information}

Local sports information was the most common information category. Programs such as Coach's Corner ${ }^{4}$ and the local sports section during the daily news broadcasts were the most common sources for this type of information. I classified local sports information as utterances relating to gathering or gaining information on the local basketball, football, wrestling, track and field, or volleyball teams and the players.

Coach's Corner was one of the most used programs in Malta for getting information on local sports teams. Several participants expressed the desire to know how the team and the players were performing. Robert Derringer said, "They give you some of the stats, just interesting to see what they have to say about the kids." Russel Lynn added, "To stay informed with the kids that are participating...sometimes he'll give an injury report." Erik Torrance, who said he only listens occasionally to the program, explained:

"Well, it's interesting to see, I don't go to the ball games, I'm not really a big sports fanatic. So it's one way to stay up with what actually happened, how certain players performed, who gave their all, who slacked and what not."

4 Coach's Corner is a seasonal program that runs during the school year on KMMR. The program involves coaches from the communities around Phillips County (Whitewater, Saco, Dodson, and Malta) discussing previous and upcoming sporting events and information related to the team. 


\section{Malta Information}

Another important local information staple was learning what is happening in Malta and Phillips County. I coded utterances as local information if a participant discussed non-sports related information about the town of Malta such as the death of a local resident, a local event, awards or honors, etc. For audience members who were 50 or older (six participants), this was where they acquired most of their local information. Participants who were 50 and older in this study admitted to using KMMR more frequently for local information than those between the ages of 28-49.

KMMR has a three programs that chronicle life in Malta. They have a daily news broadcasts, a lost and found program entitled The Doggone Gone Dog Show, which discusses local lost and found animals, and What's Happening, a locally produced program discussing local events and non-profit groups. I will be discuss daily news, sports, and weather broadcasts and What's Happening because they were the most discussed.

The daily news, sports, and weather broadcasts were heavily listened to by residents for local information. The news, sports, and weather program is read live by a disc jockey. The topics discussed include obituaries, local events, local crime stories, local human interest pieces, etc. Included in the morning news are local birthdays, area school lunches, and area school activities.

For audience members, the local news provides residents with what they need for their day-to-day lives. Teacher Leslie Kilgore commented "I guess it just prepares me for 
the day, it gets me ready, and then I kind of feel in touch with the whole community before I actually go to school."

Hospital worker Sarah Frank built upon Leslie Kilgore's comments by saying: “it's local so...if there is anything I need to know type of thing...I'm at work at 7:00am, I'm trying to get my kids organized for the day so I want to know if something's been canceled...or if something new has been added for the day."

She went on to say:

"It's kind of nice, they announce birthdays in the mornings, they announce the lunch menu, they announce a bunch of different things. So it's almost like, you know, it's just the beginning of the day, it's just a constant this is how [it is], it is the beginning of our day and now we can go on and do the rest."

Sarah further explained that she listens for the school lunch menu so she knows what her son had for lunch. Lauren Bergstrom stated that "Just to keep myself educated and up with what's the what's going on in our community and area...I again, don't have a lot of time during the day to read a ton of newspapers, so if I can catch a little local news on KMMR...I can get the headlines on KMMR.” For Pastor Graham Purks, the live news provides him with the, "most recent news of what's happening."

Obituaries were another type of local information discussed in interviews. Three participants explained why they listen to obituaries. Leslie Kilgore said: 
"They read the whole obituary on this radio and sometimes you may not know the person but certainly you know their family members and it kind of jogs your mind."

She further explained:

"I like to hear the obituaries because when you live out in the country our only real form of local news is the weekly newspaper...listening to the news when I'm in town is really important, especially cause sometimes you miss probably a funeral you should have went to because you live out there, and you just don't get that information."

Garrett Dunne said that for him it was important to learn if somebody passed away in order to make plans to attend a funeral. Erik Torrance explained the importance of obituaries, "We don't have a way to really get them out otherwise so it does give a faster notice to the people that the obituaries are being published." He went on to explain that while the newspaper publishes obituaries, it only comes out once a week on Wednesday and "if [there is a funeral]on Saturday, the only way they are going to hear it is on the radio or word of mouth."

What's Happening is another popular program discussed by participants. Kaleigh Strandberg explained its importance:

"It's good to have information on what's going on...you get the details on not only what it's going to be [an event] but you can kinda get a sense for how excited the people are putting on the event about the event and 
specifics about what's going, things you can't fit in an ad in a couple column inches."

Kaleigh uses this information to make plans if she wants to attend an event. Chris Droser told me his story of listening to What's Happening:

"I went to an event for...either the museum or the Dinosaur Field

Station...some type of deal they were raising money, and they did a What's

Happening program and they were describing what they were gonna raise money for and then of course they said they were having some type of entertainment, so yeah, I'll go to that."

\section{Business Information}

After community related information, business information was the next most obtained information from local residents. I coded utterances as business information if a participant discussed information that he or she obtained was related to his or her business. The business reasons iinclude: agricultural information, non-agricultural information, and making sure information is being read correctly.

For the farmers and ranchers I interviewed, KMMR was one of the most important sources of agricultural information. Russel Lynn, who spends most of his day in his fields, stated:

"Say for market reports, I guess if ya have some cattle to sell in a certain period of time you kinda see if they're gonna go up or down and then decide if you're gonna sell at that, that week or something." 
Robert Derringer echoed Russel's statements by saying:

"[I listen] To see what the markets doing and try to follow what they're doing. Like tomorrow, we are selling our calves on video, so we kind of want to know what it's going at."

For local farmers, knowing the prices of agricultural commodities is imperative for their businesses and when they spend most of their days away from home, the radio is the most efficient way they can acquire news.

Other residents also listened for the agricultural reports. Pastor Graham Purks stated that:

"I also like listening to the Ag reports...I know if cattle is going up or down, I know if wheat is staying up or down or staying the same, I know if hogs are going, because that's a big part of my ministry."

Graham's congregation is comprised of many individuals in the agricultural sector and it is important for him to stay current with the latest agricultural information so he can understand how members of his congregation are faring. Similar to Graham Purks, attorney Chris Droser uses agricultural information so he can keep up with the latest prices to help his clients. "I have to be plugged into the Ag community and what's going on, that's a big part of my job is dealing with Ag and Ag people, knowing what the markets are doing."

Non-agricultural business information was another important gratification for local residents. Kaleigh Strandberg explained that, in discussing the local fair coverage, she listened so she could get a sense of how many people were going to events to help 
decide if they were successful or not. Chris Droser uses the information he gets from obituaries for his business. "if we hear something about someone died, or has died, that means that we're probably going to get a phone call from a family member." Todd Fogarty said he listens to the program Voices of Montana ${ }^{5}$ and if a particular piece of information interests him, he will seek out more information from the internet and distribute the information as part of his job.

Making sure information was read correctly in press releases and ads were being played was important. Todd Fogarty listened for his advertisements and press releases: "I post things sometimes on What's Happening so I will listen to make sure it's posted." Police officer Dunne, whose listening habits are very low, stated that

"Say I had something here happen at the office and we send over a deal for them to put on the radio, then I actively go on there to listen to make sure that it's on there the way we wanted it."

Erik Torrance also checked up on the information he sends, "I always listen to my own [information]. I want to make sure they are reading them right. Some people don't know how to pronounce..." Business information is important for many Malta residents because KMMR is one of the few ways that local specific advertising, local specific agricultural information, and non-agricultural information can be presented to the public on a daily basis.

5 Voices of Montana is a regionally produced call-in radio show which discusses topics concerning life in Montana. 


\section{Weather Information}

Finally, weather was important to many Malta residents. The two discussed reasons for listening to the weather were for work and daily life. Weather information relating to work was coded as responses in which weather plays a part in an individual's job. Local farmer Russel Lynn explained, "For example, when you're haying, you don't wanna cut a lot of hay down if it's gonna rain in a day or two, so you wait for weather systems to go by and do your stuff, wait for a sunny day.” Truck driver Robert Derringer said, "Well if roads are bad or a snowstorm, I want to know what's coming. It keeps me informed as a truck driver." School teacher Leslie Kilgore said:

"Certainly if the weather's bad I know which buses aren't running so I know maybe which students I'm not going to have present in class today because they can't get, they can't get in because of road conditions." Other residents stated more personal uses for the weather.

Others used weather information was for their daily lives. Jeffrey Coleman explained that he listens to the weather so he can "find out what's goin' on...and then I can put away my cars, flowers, whatever it takes to batten down the hatches." Chris Droser added upon Jeffrey's explanation by saying:

"And the weather of course is big here, you gotta know what's going on, whether you're going to put your cars in or if you're going to go fishing in the afternoon how hard the wind is going to blow, storm warnings in the winter is very important, whether there is going to be a storm coming or how you're going to prepare for it, or if you're kids are scheduled to be 
shipped out on a Speech and Drama bus at four in the morning you'd kind of like to know what the weather is going to be like when they're out on the road."

\section{Enjoyment}

Audience members who listened to KMMR also sought out enjoyment (pleasurable experience derived from a medium) as gratification (Sparks, 2012). According to the interviews, more listeners who were 50 or older(eight total) reported obtaining enjoyment from KMMR then those members who were 28 to 49 (six total). Utterances were coded as enjoyment if a participant discussed a pleasurable experience while listening to the radio. After coding had been completed, four distinct categories emerged as to why residents listen to KMMR for enjoyment. The categories were programs (local, regional, and national and excluding live sporting events), music, Malta residents on the radio, and sporting events. The first category I will discuss will be programs.

\section{Programs}

For the participants, programs gave listeners enjoyment. Programs that brought enjoyment ranged from political (The Huckabee Report and Voices of Montana ${ }^{6}$ ), to the educational (Under the Hood ${ }^{7}$ ). For this section, I will be discussing the two most discussed types of programs: political and music.

6 A regionally syndicated call in show dedicated to Montana issues.

7 A syndicated program offering advice on car repair. 
Political programming attracted three residents because they enjoyed hearing arguments on the radio. Chris Droser explained, "I just enjoy the give and take on both sides...maybe it's my nature, just kind of enjoy the devil's advocate of the argument." Jeffrey Coleman, who listens to Huckabee as well, stated:

"I get enjoyment. I really do because he picks a part a lot of people and a lot of things and a lot of factions that are absolutely out of control and he just, he just like straightens them out."

Kaleigh Strandberg enjoys the ranting callers on Voices of Montana:

"Sometimes it makes me mad...And sometimes they do have interesting discussions and have interesting guests...and then like I said the callers are just ranting and raving and it's kind of interesting to listen to for nothing else."

Enjoyment obtained from political programming appeared to come from conflict, and in the case of Jeffrey, seeing sides that he disagrees with being "straightened out."

Music programs also brought enjoyment to audience members. While discussing Grassroots Gold, a classic country and western program, business owner Roberta Glass stated, "I like the history because they're always giving you the history of that song or that singer, just a nice easy going listening program." Banker Lauren Bergstrom enjoys Grassroots Gold as well:

"it's harder to find that kind of music and so it's kind of a nice program that has a nice mix of music that maybe I wouldn't know the names, ya 
know if I wanted to seek them out on the internet...so you can go to a program like that and they give you a good variety of music like that."

The enjoyment derived from Grassroots Gold came from the scarcity of particular type of music. Grassroots Gold offers listeners a chance to hear music from a bygone era while providing them information about the artists and the music scene.

Another musical program that brought enjoyment was a locally produced program called The Polka of the Day. The Polka of the Day is a weekday program aired before noon which features a classic polka song. This program appeared to be popular among listeners 50 and older. Pastor Graham Purks, for example, grew up in a city known for polka and the songs bring him back to his childhood:

"I love The Polka of the Day...because I grew up in [city] and at one time it was labeled itself the Polka Capital of the United States and so that takes me back."

Roberta Glass explained the show "perks" her up and Rita Hoener said listening to it is a joke between her and her husband. The enjoyment participants get out of The Polka of the Day speaks to the different connections they have with the music: Graham has a connection to polka music from his youth, Roberta enjoys the liveliness of the music, and Rita gets enjoyment sharing a laugh with her husband.

\section{Music}

I separated the play-list music that KMMR plays every day from the music programs discussed above because of the difference between them. The play-list music that KMMR plays every day is not created around a theme (such as a countdown) and is 
not hosted by a celebrity host. It is the entertainment between programs, not a program itself. Of the participants interviewed, only those in the 28 to 39 age bracket did not listen to music on KMMR for enjoyment. One of the most talked about aspects of music that was discussed by participants was the recent change in format. In 2012, KMMR shifted it's night time music selection from current adult contemporary to classic rock and pop of the 1950s, 1960s, 1970s, and 1980s to help match the listening audience's taste. This change was met with great enthusiasm by many local residents. Leslie Kilgore explained, "And now they're playing the songs that I like. Did I always use to listen at night? No, not until they went to playing the 60 s, 70 s, 80 's music..."

Graham Purks explained why he likes to listen to music:

“There was a period where, ya know, more high school DJs were hired in the evening and some of the current music I just, I'm just an old geezer. I like the music of my youth..."

Roberta Glass expressed a similar sentiment by stating "I like it. It's my music. I grew up in the 60's. I like it, and I'm getting used to the western too. I just enjoy it." For many of the older residents, the music is their music: the music they grew up with and the music they feel most comfortable with. This was an important shift for KMMR as seen above because the night shift was a shift that was not popular among the 50 or older population which is the group that listens to and advertises on KMMR the most. 


\section{Residents on the Radio}

The next area of enjoyment for listeners was the inclusion of local residents on the radio. This type of enjoyment was mostly discussed by the audience members who were 50 and older. Erik Torrance stated:

"Whenever they're doing a fundraiser, especially for like the Fourth of July fireworks and you have Greg Kielb and you have James Smith, and you get Phil Roberts, and they you know, off the cuff cutups and whatnot it's always fun to listen to them interact."

Graham Purks added to Erik's explanation: "Their banter back and forth is just so much fun. It invites you into their relationship or their friendship over radio."

In addition to banter between friends, some audience members also enjoyed hearing residents talk on the radio. Graham Purks discussed how a local football star had been interviewed on a regionally produced program. "To...hear how humble and sincere of a young man he is as a product of this community was fun." Rita Hoener enjoys listening to hear how disc jockeys grow as announcers:

"it's always fun to listen to the new DJs as they learn to speak on the radio because that is a trick that I don't think they realize it till they get the job and have to pronounce all those words and things. It's just a form of entertainment that is there."

\section{Sporting Events}

The final type of enjoyment discussed was listening to the live sporting events. Only three individuals made explicit statements of listening to live sporting events for 
enjoyment (others listened for excitement), and for these residents they have a deep passion for sports. Greg McNulty, former athlete, explained he listens because it is, "Entertainment. I'm interested primarily in basketball and football...Greg Kielb paints as clear a picture as any announcer I've ever heard, so it's pretty nice to sit at home.” Todd Fogarty listens because he finds sports events entertaining because his children are in the school system, but he will only listen to the coverage if he has no way to make it to the game. Russel Lynn, a former Malta athlete, said he liked to listen because, "I like to hear us win" and, like Todd, he will listen only if he cannot make it to a game. One reason for the low response rate to this gratification could be due to the fact that many residents attend the sporting events, in fact, many participants stated they do attend sporting events and that the live sporting broadcasts are of great benefit to the elderly who are not able to go to the events.

\section{Creating Social Interaction}

Creating social interaction (refers to how media triggers interaction) was one gratification that participants did not actively seek from KMMR, but it was the third most obtained gratification (Sparks, 2012). This could be explained due to the fact that residents do not intend to listen to KMMR for social reasons, but instead want to get information. Of the sixteen participants, twelve explicitly stated that they obtained social interaction from listening to KMMR. Utterances were coded for social interaction if a participant discussed interacting with another individual about items he or she heard on KMMR. 
Several audience members being able to participate in conversations about local sports. Four participants mentioned social interaction with sports information in relation to their jobs. Leslie Kilgore explained:

"The reason I listen is because for the most part I have lots of the kids in my classrooms and it's a good way to connect with my students and talk about maybe the touchdown they scored, or how many baskets they scored. I guess its just a good way to keep in contact with my students." Graham Purks discussed using sports information to "talk to people, my business, my job, staying in touch." Sara Frank explained she wants to seem sincere in her discussions:

"I use it because people will, ya know, come into the office and they wanna talk about it and then you can say 'Oh I know, isn't that awesome!' without lying."

Veronica Matisse explained that when she is working in the kitchen at her cafe, she will listen to the sporting events so she can shout the scores out to the patrons of her restaurant.

Other than for work, several participants discussed using local sports as a way to engage with individuals in Malta. Jeffrey Coleman stated:

"Anytime I hear stuff like that I'm one of the first people to bring it to other people's attention. Like if I hear something on the radio about Rick Jones or somebody being MVP, I'll say 'Did you hear that, did you hear that?' I bring that to everybody's attention, I like that." 
Rita Hoener uses sports information to stay in contact with friends who live in other communities:

"I have friends all over the state and sometimes I hear about their children and what they're doing, or I hear about relatives cause I have relatives all over the state too...Sometimes I call my friends to tell them I heard their son's name on the radio or whatever."

Living in a small town, Lauren Bergstrom feels that she needs to stay educated about local sports so she can congratulate local players and talk with their parents: "You might see that high school kid in my place of employment or at the grocery store and I congratulate them, visit with their parents 'I heard he was doing great.' Again it's a small town so you run into people all the time and it's nice to know a little bit about, ya know, the kids and the sports."

Sarah Frank uses sports information as a way to carry on conversation with local residents both at work and at church:

"I use it to carry on conversations with some of these older folks that are tied to their radios and all they want to talk about in their life is whatever's going on during the football season...we go to the [local church]...and in the fall my son'll be there and he's in football, and there's two older men who are probably in their 80s and all they wanna know is 'How did your football weekend go? What did you do?' And I use that information to be 
able to have a conversation and be part of that. And then they feel great too. They feel like, I think, maybe they don't feel as old."

News items that are heard on KMMR also provide listeners with information to engage in social interaction. Sarah Frank discussed how KMMR helps her have conversations with her son about food choices and her son's day at school:

"So when I hear the lunch menu in the morning then when I get home I can say 'Oh, well ya know they served, did you have that?' 'No.' Then I give them the other option...but I would say at least two or three times a week we have a conversation. But then it starts out with 'What did you have for lunch?' and then moves into 'So what did you do in Spanish class?' So it just kinda helps me roll along."

In addition to discussing food choices, Sarah uses the lunch menu information as a way to discipline her son when he makes exaggerated statements about what was served at lunch:

"We have dinner every night and we sit down and it starts out with 'We ate kangaroo meat today.' or something like that, and I don't like that stereotype that the kids think they need to say those kinds of things...And of course he jokes he, doesn't actually say 'We ate kangaroo meat.' He jokes 'So and so says we ate kangaroo meat today.' And I say 'Allen, let's backtrack here'...I use it as a almost a disciplinary 'don't do this' type of thing." 
Leslie Kilgore, whose husband stays primarily at their ranch and does not receive reception from KMMR, also discussed the importance of radio and conversations with family:

"certainly my husband and I discuss it because he lives out in the country so he misses all that, so every night when we visit on the phone, because we have two homes, we talk about what goes on, what's happening in Malta. It's a way to keep him connected to the area too."

Kaleigh Strandberg uses local information to have work conversations because, "you need to have that information to participate in those conversations about how we can improve events here in Malta."

As stated previously, only one participant discussed seeking out KMMR for creating social interaction, yet twelve residents made explicit reference to it in terms of conversations at work, conversations with friends, conversations with family, and conversations with townspeople as a gratification obtained. This was a gratification that people did not immediately think of but is of great importance to many participants as it allows them to cheer up others, spread information, congratulate individuals, perform better at work, and help maintain social bonds.

\section{Internet Impact}

Residents of Malta have had access to high-speed internet since the early 2000s and in 2012 fiber optic internet was introduced into the town. Research Question Three asked, "In what ways has the availability of the Internet impacted community members' perceived use of their local radio station for fulfilling gratifications?" In answering this 
question, I relied on uses and gratifications and niche theory to see what gratifications people were obtaining from the radio and the internet and how the characteristics of each medium factored into an individual's choices for medium use. I created a series of questions (see Chapter 3) which prompted participants to talk about what gratifications they obtain from the internet, and why they used the internet instead of the radio to obtain gratifications. During the coding and analysis section, I coded utterances which described specific gratifications obtained from using the internet.

I discovered that fifteen of the sixteen residents use the internet. Recall that the radio was used most by the 60 or older age group and the least used by the 28 to 39 year old age group. What I discovered with internet use was the opposite: internet use was the most frequent amongst participants who were in the 28 to 39 age range. Internet use was inversely related to age, with the 60 and older group using the internet the least. Only one resident did not use a computer or the internet: Robert Derringer. When asked why he does not use a computer he said, "Probably because I never learned it and when I was on the ranch full time I, we didn't have one and never needed it up there." For Robert, the internet is not integral to his life and even though he stated that he now has access to it, he remains not interested in using a computer.

\section{Media Characteristics and Impact}

Niche theory states that the gratification opportunities of a medium will impact people's use. Due to this, I asked a follow up question to participants if the schedule of programs impacted their listening and whether they would use the internet due to its more 
flexible schedule. The internet appears to have minimal impacts on audience members' listening habits. When asked if a radio schedule impacts listening habits, only one participant, Greg McNulty, appeared to have been impacted, but as he explained his internet habits were formed before he arrived in Malta and he explained his use of the internet as, "I would be in the generation that is used to getting it now." The rest of the interviewees, however, the internet had little impact on radio use, and this was most apparent for audience members who were 50 or older who preferred to use the radio. For four of these participants, the radio schedule is a part of life. Chris Droser explained: "I do have to conform my schedule to them, but ya know, everywhere in life you will have to conform a little bit to somebody else's schedule or somebody else's desires...as opposed to what you want, you can't always have your way."

He went on to say:

"So I guess I take that as a drawback to radio, but I think there are so many other things that are good about it. Now I say 'I have to conform to their radio schedule.' Ah, I will do that because I like the medium... and I've got the internet, if I want to look at something I can, but I would prefer the radio."

Erik Torrance echoed this sentiment during our interview by saying "Anything's got to be on a schedule." Roberta Glass and Leslie Kilgore felt the same way, but for them a schedule is important because they know when to listen for programs. But some accommodated the schedule because they were loyal listeners. According to Graham, 
listening to the local radio is about community support, not convenience. "I think that's a fault of society that we want to do it on our own instead of respecting a larger group at stake." Graham went on to explain that he has the option of listening to the podcast version of The Huckabee Report if he misses the program on KMMR, but he chooses not to. If he wants to hear the program, he will listen to the local radio and if he misses it, then he should have been paying better attention. Graham felt supporting a local institution outweighed meeting his media needs.

\section{Gratifications from the Internet and Impact}

Internet use among the 28 to 39 age group appears to occur more often than with the 40 or older age group, but the internet has had very little impact on radio use for the different age ranges. One area though where there was an impact was in obtaining weather information, and this was most present in the 28 to 49 age group. Greg McNulty stated that he only gets his weather information from the internet. Sarah Frank, Lauren Bergstrom, and Garrett Dunne stated that they get more of their weather information from the internet than the radio. Sarah Frank only listens for weather in the morning before going to work so she knows what to expect for the day; otherwise she uses an internet weather site. Garrett Dunne will only listen for the weather in his vehicle in the morning when he is on his way to work; otherwise he will use his smart phone. Lauren Bergstrom was the most conflicted on her weather use:

"Sometimes I feel KMMR might have more local weather and I might actually believe their weather more than something I find on the internet, but I probably wouldn't wait, I would look it up on the internet." 
Lauren trusts KMMR's weather information more than the information she gets from the internet, but due to her busy schedule, she is resigned to looking it up online.

As Greg McNulty explained, he came to Malta with his internet habits firmly established and from the interviews I conducted it appeared that each participant had a radio and internet habit, and the two are rarely in competition with each other, except in the case of weather information for the four participants in the 28 to 49 age range. One reason for this could be because the internet and the radio are in a symbiotic relationship. Todd Fogarty, Russel Lynn, and Chris Droser (all in the 50 to 59 age range) stated that they use both the radio and will seek out more information from the internet on topics they heard on the radio. Todd Fogarty explained that he will often augment KMMR's weather report with information he can get from internet weather websites and if he hears information he finds interesting on a program, he will turn to the internet to find out more about it. Chris Droser echoed Todd's statements by saying:

"If I hear on the radio there's a big storm coming in, I can pull up the weather map on the internet and see where the Doppler Radar tells me it is and which way it's moving and things like that."

A second reason why the internet and the radio are not in competition with each other is because they service different needs. Rita Hoener stated, "I use the internet for needs that aren't met by the radio. If it was met by radio, I probably wouldn't use the internet." Discussing the different needs the two mediums service, Chris Droser explained: 
"The radio definitely for all your local things. The internet...my social media is email...the speed at which you can transfer information, or transfer pictures, or download things...or order parts for my pressure washer."

Many of the Malta residents I interviewed have placed the internet and radio into separate niches which fulfill separate needs. Gratifications obtained from the internet included: information (checking weather information, checking bank accounts, reading online newspapers, and searching for home improvement ideas); social interaction (keeping up with friends and family on social media); purchasing goods that are not available in Malta, and entertainment (watching videos online and streaming music that is not available on KMMR). With the exception of weather information and news, KMMR cannot plausibly fulfill all of these needs. While the internet and the radio are two separate mediums, an interesting convergence has taken place for KMMR: online streaming of live sporting events. This is an area where KMMR has embraced the internet for its audience. Rita Hoener remarked "Well when I'm in Arizona that's how I listen to the games." Leslie Kilgore stated that she "Certainly listens to the sports broadcasts because I can't get them out there [on the farm].” Owner Greg Kielb told me of a time when he received an email saying "Sounds good from Barcelona!" from a former Malta resident who was listening to a sporting event. Chris Droser commented about a past basketball championship that Malta was in: 
"We had a group of our National Guardsmen [who] were stationed in Afghanistan and some of them were listening to it, so that broadcast of local radio over the internet, it means a lot to a lot of people." I asked Chris what was important about having KMMR stream sports coverage and he explained:

"It's that small town connection, it's still their home town...if you lived here, grew up here, have all your extended family here, maybe that kid that's playing basketball is a relative of some sort, and they all cheer for Malta."

This final gratification combines radio and the internet into one for the purposes of reinforcing personal identity (McQuail, Blumler, and Brown, 1972). To those residents who are serving overseas, who travel away from Malta in the winter, live outside of signal range, or former residents who live in a different area, the internet is a way to get the enjoyment and excitement out of a sporting event; it is also a way for people to stay connected and reinforce their personal identity as a Malta resident. It gives these individuals the opportunity to take pride in their town, feel a part of the community, and celebrate the accomplishments though they may be thousands of miles away. 


\section{Chapter 5}

\section{Discussion}

The current study focused on the gratifications sought and obtained from a local radio station in a rural community and the impacts that the internet has on audience members' use of the station. The idea of how the internet has impacted a rural audience's use of its local mass media has not been discussed in-depth in recent literature. Due to the lack of literature on this topic, I felt that it would be beneficial to learn about the current media landscape in a rural community after the introduction of a new medium into the media environment.

In the current study, the findings suggest that the internet has not seriously diminished the use of the local radio station. The findings alleviate some of the fear put forth by Craig (2009) who worried that the introduction of the internet would lead rural individuals to use their local radio less. This study showed otherwise: a majority of the audience members interviewed have a reliance on the radio regardless of using the internet. The findings suggest that the internet and the radio have a symbiotic relationship where the internet fulfills the needs that cannot be met by the radio and at times, the radio can steer audience members to the internet if they want to know more about a topic. The findings also suggest that those in the 50 and older age group use the radio more than those who are 28 to 49 because they are reliant on the radio for obituaries, funeral announcements, local events and other news that connects them to the community. In addition, those who are 50 and older tend to rely on the radio (more so than the other cohorts) as a source of music. The station's format has been tailored to the 
songs that were popular when the 50 and older individuals were growing up. Finally, I found that those in the 28 to 39 age range use the internet more frequently than they listen to KMMR.

These findings suggest a partial displacement for younger audience members (28 to 39) who use the internet more than those who are 40 and older (Dimmick, et al., 2000). The difference in radio use could be explained by the under- 40 age group having more exposure to new technologies as compared to the older listeners. Still, the under-40 age groups use the radio for local advertising, local news, and local sports.

Gratification opportunities are defined as the "characteristics of a medium" relating to "time, space and content" (Dimmick, et al., 2004, pp. 22-23). Radio and internet differ in their flexibility. While the internet offers more opportunities for audience members to listen or search at their leisure, the radio relies on a set schedule. Many residents interviewed said that they were not bothered by the rigid schedule of radio. Some residents reported that a schedule is a part of life and a schedule is how one knows when something is going to be aired. Only one resident (Greg McNulty) expressed displeasure at a radio schedule saying that he was in the "instant gratification generation." In general, across all age groups, the flexibility of the internet was not a characteristic they discussed.

With regard to content, residents would turn away from KMMR for specialized content not found on KMMR. For example, some residents discussed that they will occasionally listen to music on the internet because they cannot get their certain types of music on KMMR. Another resident preferred the internet because she was moving and 
looked on Craigslist to find apartments in a new city. Another resident used the internet to look up home improvement ideas.

One notable exception where the radio has been displaced by the internet is weather. Those in the 28 to 49 year-old range stated they were more likely to seek weather information from the internet. This appears to occur only in the younger age range as participants in the 50 to 59 age range state they supplement their radio weather information with internet weather information, and the 60 and older group did not talk about weather information on the internet at all.

Finally, the concept of location was not seen as a problem for residents. Most residents listened to KMMR either in their vehicle (twelve participants), at work (seven participants), or at home (seven participants). Ten participants stated they listen to the radio in multiple locations, such as their house and their vehicle. The findings suggest that during a typical day for these participants, a radio is usually near them and they have the opportunity to listen to KMMR.

Niche theory suggests that a new medium has the potential to displace or partially displace an existing medium if the newer medium offers more gratification opportunities. Most of the participants I interviewed are content with the radio, which appears to offer them more gratification opportunities. In addition, they say radio has the content they want and they can access the radio almost anywhere.

The participants in this study showed that KMMR and the internet are rarely in direct competition with each other, as suggested by Dimmick, et al., (2004) who stated that the internet and the radio offer different gratifications. For the audience members in 
this study, the internet was used for material consumption (buying items unavailable in Malta), social interaction with individuals who live away from Malta (email and Facebook), visual entertainment (movies and YouTube videos), work (looking up information and filling out paperwork) and keeping up with trends (fashion and home improvement). The radio, on the other hand, is used by residents to obtain local information (business, community, and sports), audio entertainment (music, Malta residents being interviewed on the radio, musical and political programs), and to help initiate social interaction with residents and occasionally with non-residents. The findings suggest that Robert McChesney is correct in his assessment that while the internet offers a plethora of information and entertainment to those who use it, the local radio is still the best medium to find out local information (as cited in Hilliard \& Keith, 2005, xi). In Malta, local information was the most sought and obtained gratification by audience members.

The study also found that the Malta residents who are tuning into KMMR are fulfilling the gratifications they are seeking. The study found that residents seek and obtain two of the same gratifications from the radio: information and entertainment, showing that KMMR is meeting the expectations of the audience members. The largest difference was in social interaction. Residents do not seek out social interaction directly from listening, but they are able to use the knowledge they have gained from listening to carry on conversations and share experiences with other residents, and on occasion, nonresidents. This finding suggests that social interaction is a latent gratification for audience members and is important as it allows the audience members to interact with 
fellow residents at work places and outside of work. Since Malta is a small community, many of the residents know each other and KMMR helps to provide information that is integral in creating a sense of social cohesion. For example, several participants discussed how they like to compliment an athlete or an athlete's parents, about a sporting event.

The study also shows that KMMR has embraced the internet by streaming broadcasts of sporting events over its website. This is an important step for KMMR as current and former residents who are not within the signal range can now listen to sporting events on KMMR's website. From anecdotal evidence provided by Greg Kielb and Chris Droser, it appears that individuals who are away from Malta have a desire to keep a link between themselves and their community. In addition, Greg Kielb stated that he is working to get a twenty-four hour live stream set up for KMMR. This would allow KMMR to continually broadcast and let individuals connect with and listen to the station when they are away from Malta.

The most troubling aspect of this study is that the 28-39 year old audience members listen to KMMR less than the older residents. With Malta having a large elderly population, the future of KMMR could be in jeopardy as the 39 and under audience members either move away or continue to rely on the internet and other mediums, such as satellite radio (another frequently talked about medium), and focus less attention on KMMR. In addition, as participant Rita Hoener stated during our interview, Malta is an economically depressed community and this also could have an impact on KMMR's future. But, according to the interviews I conducted, local businesses advertise on KMMR not only for brand recognition, but also to support an institution that provides a 
unique service for the community. Three business owners expressed that failure to advertise on KMMR could spell the station's demise. For the residents that would mean the loss of one of the most important sources of daily local information and entertainment.

\section{KMMR Production}

The data that I collected for the production side of KMMR was not fully capable of answering Research Question 4: "What types of gratifications do producers at a local radio station perceive the station fulfills within the listening community?" and Research Question 5: "In what ways do producers at a local radio station perceive the availability of the internet has affected the types of gratifications sought and obtained among listeners." After I had conducted the interviews and was coding the data for the production side, I noticed that two out of the four members of the production side offered answers that were either hyperbolic or referred me to talk with Greg concerning production choices. Thus, I decided that I could not make a strong argument with only two out of the four individuals remaining in the study. Although I was not able to answer these questions, I did gain insight into how producers make programming decisions and the views that the producers have about KMMR's connection to the local community.

One aspect concerning KMMR the producers discussed was how the station reflects the interests Malta. For the producers, KMMR is about the community. Claudette Kielb told me that they are, "A community-minded radio station." The programs on KMMR reflect the interests of Malta. For example, local sports are important to community members and Coach's Corner was created as an outlet for 
coaches to discuss their teams. Greg Kielb told me that he believes people, such as friends or relatives, tune in to hear how a specific player has been performing. Kelly Korsbeck told me that Coach's Corner is one way for residents to keep tabs on the local players. This sentiment was reflected by audience members, such as Leslie Kilgore and Lauren Bergstrom, who said that they listen to information about sports so they can talk to players about what a wonderful job they have done in the past week. In addition to sports, the producers know that KMMR is the only daily news source for community members so they have created programs to highlight events that are going to occur in Malta. The What's Happening program was designed as a local public affairs program so that local groups could inform residents about upcoming events. The program is designed to help the groups and create interest in the community and this was shown in my discussion with Chris Droser who attended a local event he originally did not know was going to occur.

In addition to community related news, KMMR also works to be communityminded by setting up fundraisers to help community members in need of assistance. KMMR hosts radio-thons for residents who require major medical procedures or have had a catastrophe befall them. Radio-thons have been created as a way for community members to band together to help a fellow citizen (or citizens) in need. Greg and Claude Kielb see it as part of their duty to the community to host these radio events because they have a medium that can reach everyone in Phillips County. From my experience working at KMMR, I recall an instance where an apartment complex burned down on Central Avenue (Malta's main road through town) and KMMR held a radio-thon for the victims 
of the fire. The donations were distributed to the people who had lost their residence and belongings as a way for them to recover from their disaster. When I asked Kelly Korsbeck if a larger community, such as Havre, Montana, would hold a radio-thon for someone in need, he told me that he doubted it.

Greg Kielb is able to tailor programs specific to Malta because he believes that he should have open communication with his audience. Greg told me that if anyone comes to him with a critique on a program, he will talk with them about it. Greg described to me a specific time in which he was open to his audience in regards to music selection. The situation Greg discussed with me concerned the statements The Dixie Chicks made in 2004 about President Bush concerning the shame they felt from him being from Texas. This resulted in KMMR pulling The Dixie Chick's music from rotation and having disk jockeys announce during each hour that we would not be playing their music on this station. He told me: "I I know it offended a lot of people in the area just from coffee shop talk and so on.” When I asked Greg if he made his decision to pull The Dixie Chick's music from rotation based on this word of mouth he said, "I really did, yeah, I really did." This idea of being in touch with community members is how Greg keeps his station relevant to the local audience. Claudette Kielb, Greg's wife, said that Greg is:

"One of the biggest bullshitters around, but that's why they like him, he's interested in what people say. He doesn't just ignore them...If somebody says 'Ya know, so and so did this on the air' he will make it right. And if 
somebody gives him a suggestion, face to face, or sign your name, or call, he's right there on it."

Greg strives for his station to be what disc jockey Joyce Robinson called the "Heart of the community." In Malta, KMMR is at the heart of the community because it works to keep the town functioning. This is accomplished by creating programming that offers audience members information that is relevant to their community and fostering a sense of community by airing local sporting events and interviewing local residents on the air. It is a station where people can go to hear about a lost or found animal on The Doggone Gone Dog Show or learn about a local event coming up from What's Happening. It is a station that farmers can listen to in their combines and tractors for upcoming rainstorms which could affect their harvest or ranchers can listen to for the purchase price of cows and pigs. It is a station where people can call in if they need to post about a garage sale or call in if they find a stray animal. It is a station that is engineered to meet the needs of Malta and to do so out of a sense of public service.

\section{Limitations}

The study has limitations. The first limitation is the sole use of qualitative methods for data collection. A quantitative study may have resulted in more generalizeable results through the collection of more data by having a larger sample size and using a survey as the data collection instrument. But as this was a case study, a smaller sample size and interview methods were used to obtain more context rich data. 
The second limitation is the very nature of a case study. A case study explores one particular phenomenon and while showing depth, is not generalizable. This study could have benefited from being a multi-site study with the researcher interviewing residents in other communities about their local radio station. Due to budgetary and time constraints, this could not be accomplished.

The third limitation is the requirement of confidentiality. While in Malta, I was asked repeatedly where I was staying and who I was interviewing. Due to confidentiality and anonymity protocols, I was not allowed to give out that information to individuals and this resulted in me appearing standoffish, as explained by one of my informants. Many residents, off and on record, informed me that in Malta, there is no anonymity or confidentiality (I was told "There are no secrets in Malta"), and that everyone knows everyone's business. I did explain to many Malta residents that because of the need to respect privacy and the laws concerning anonymity and confidentiality, I could not divulge information, but doing so made me appear standoffish and less trustworthy. This became apparent in interviews I conducted where many participants gave short answers. This limitation resulted in some participants not providing me with in-depth explanations of their media choices.

\section{Future Studies}

For future research, a comparison study of locally owned radio stations and corporately owned stations in rural communities should be explored for audience members' uses and gratifications. This research could be performed along the Hi-Line with a comparison study being performed between KRYK in Chinook, Montana and 
KMMR in Malta. Future research concerning rural mass communication could explore what happens when a medium is out of service. During the course of my interviews, I had one participant discuss a time when KMMR went off the air and how that affected her. Another participant stated that you do not fully appreciate KMMR until it is gone. In an area like Malta, with one weekly newspaper and a daily radio station, it is important to understand what the impacts are when the local radio goes off the air.

Finally, an ethnographic account of rural radio production should be performed. Though this study did not yield data that could answer the research questions, my experiences with the producers and some of our discussions highlighted their ideas of KMMR's role and how the producers work with community members to create a station that functions for them. For example, Claudette Kielb described Greg as a man who takes care of his accounts, he is out in the community talking with business owners and residents, taking their compliments and critiques and always working on ways to correct any problems individuals have with the station. An ethnographic account of a rural radio station could offer insight into the connection between those who run the station and the community they serve. It would show how programming decisions are made and the role a community can play in a station's formatting decisions.

\section{Conclusion}

The current study aimed to understand the relationship between a local radio station, a small rural community, and in what ways individuals use the internet. The findings of this study helped highlight a section of communication studies that does not get discussed often: the rural communication experience. While books have been written 
on the topic, research into rural radio in the $21^{\text {st }}$ century is comprised of what possibly will happen. The findings from this study help show that local radio is not a thing of the past and in this rural area resident the internet has not displaced the local station. New technology for many residents is a source to gratify needs not met by the radio, but has not made the radio obsolete as it is the most important source for local information, creating shared experiences that helps order people's days, and creates common talk that deepens their connections. 


\section{References}

Babbie, E. (2013). The Practice of social research. Belmont, CA: Wadsworth

Ball-Rokeach, S.J. (1998). A theory of media power and a theory of media use: Different stories, questions, and ways of thinking. Mass Communication \& Society, 1. pp. $5-40$.

Baxter, P., Jack, S. (2008). Qualitative case study methodology: Study design and implementation for novice researchers. The Qualitative Report, v.13. pp. 544-559

Berg, B.L. (1989). Qualitative research methods for the social sciences. Boston, MA: Allyn \& Bacon.

Berelson, B. (1949). What "missing the newspaper" means. In P.F. \& F.N. Stanton (Eds.) Communications research. (1948-1949). pp. 111-129. New York: Harper.

Blumler, J. (1979). The role of theory in uses and gratifications studies. Communication Research, v. 6. pp. 9-36. Doi: 10.1177/009365027900600102

Craig, S. (2009) Out of the dark: A history of radio and rural America. Tuscaloosa, AL: The University of Alabama Press

Cromartie, J., Parker, T. (2012). Rural classifications. USDA Economic Research Service. http://www.ers.usda.gov/topics/rural-economy-population/ruralclassifications.aspx

Dimmick, J. \& Wallschaeler, M. (1986). Measuring corporate diversification: A case study of new media ventures by television network parent companies. Journal of Broadcasting \& Electronic Media, 30. pp. 1-14. 
Dimmick, J., \& Albarran, A. (1994). The role of gratification opportunities in determining media preference. Mass Communication Review, 21. pp. 223-235

Dimmick, J., Kline, S., \& Stafford, L. (2000). The gratification niches of personal e-mail and the telephone: Competition, displacement and complementarity. Communication Research, v. 27. pp. 227-248

Dimmick, J., Chen, Y., \& Li, Z. (2004) Competition between the internet and traditional news media: The Gratification-opportunities niche dimension. The Journal of Media Economics, v. 17. pp. 19-33.

Feldman, E.J. (1981). A practical guide to the conduct of field research in the social sciences. Boulder, CO: Westview Press

Field, H., \& Lazarsfeld, P. (1946). The people look at radio. Chapel Hill, NC: The University of North Carolina Press.

Gans, H.J. (1979). Deciding what's news: A study of CBS Evening News, NBC Nightly News, Newsweek, and Time. New York, NY: Pantheon Books

Herzog, H. (1944). What do we really know about daytime serial listeners? In P.F. Lazarsfeld \& F.N. Stanton (Eds.) Radio Research. (1942-1943). pp. 3-33. New York, NY: Essential.

Hilgenberg, H. (2010). The Current: Balancing localism in radio. (Master's Thesis: University of Minnesota).

Hillard, R.L. (2003). Farm and rural radio in the United States: Some beginnings and models. In Girard, B. (Ed.).The One to watch: Radio, new ICTs, and interactivity. 
pp. 201-208 Rome, Italy: Food and Agricultural Department of the United Nations.

Hilliard, R.L, Keith, M.C. (2005). The quieted voice: The rise and demise of localism in American radio. Carbondale, IL: Southern Illinois University Press.

Hilmes, M. (1999). Radio voices: American broadcasting, 1922-1952. Minneapolis, MN: University of Minnesota Press.

Hood, L. (2007). Radio reverb: The impact of "local" news reimported to its own community. Journal of Broadcasting \& Electronic Media, 51. pp. 1-19.

Huntemann, N. (1999). Corporate interference: The commercialization and concentration of radio post the 1996 Telecommunications Act. Journal of Communication Inquiry, 23. pp. 390-407.

Katz, E., Blumer, J.G., Gurevitch, M. (1973). Uses and gratifications research. The Public Opinion Quarterly, 37. pp. 509-523

Katz, E., Haas, H., Gurevitch, M. (1973). On the use of the mass media for important things. American Sociological Review, v. 38. pp. 164-181

Katz, E. in Griffin, Em. (2012). A first look at communication theory. McGraw-Hill College.

Lindlof, T.R. (1991). The qualitative study of media audiences. Journal of Broadcasting \& Electronic Media, 35. pp23-53.

Lindlof, T.R. (1995). Communication research methods. Thousand Oaks, CA: SAGE Publications Inc. 
McGuire, W.J. (1974). Psychological motives and communication gratification. In J.G. Blumler and E. Katz (eds.) The Uses of mass communications: Current perspectives on gratifications research. Beverly Hills, CA: Sage.

McQuail, D., Blumler, J.G., \& Brown, J.R. (1972). The television audience: A revised perspective. pp. 135-165. In D. McQuail (ed.). Sociology and mass communication. New York, NY: The Free Press.

N.A. (2012). Population of the city of Malta, Montana. Census Viewer. http://censusviewer.com/city/MT/Malta.

N.A., 2013. USDA rural development-about rd.

http://www.rurdev.usda.gov/AboutRD.html

N.A. (2012). US Census, 2011.

http://factfinder2.census.gov/faces/tableservices/jsf/pages/productview.xhtml?pid=DEC_ 10_DP_DPDP1

Palmgreen, P., Rayburn, J.D. (1979). Uses and gratifications and exposure to public television: A Discrepancy approach. Communication Research, v. 6. pp. 179. Doi: $10.177 / 009365027900600203$

Quammen, D. (2012). Riding out another season. National Geographic. http://ngm.nationalgeographic.com/2012/01/northern-montana/quammen-text

Rubin, A. (1985). Use of daytime television soap operas by college students. Journal of Broadcasting \& Electronic Media, 29. pp. 241-258.

Rubin, A. (1993). Audience activity and media use. Communication Monographs, v.60. pp. 998-105. 
Santhanam, L.H., Mitchell, A., \& Rosensteil, T. (2012). Audio: By the numbers. The State of the News Media 2012. http://stateofthemedia.org/2012/audio-how-farwill-digital-go/audio-by-the-numbers/

Schramm, W. (1964). Mass media and national development: The Role of information in the developing countries. Stanford, CA: Stanford University Press.

Skuse, A. (2002). Radio, politics, and trust in Afghanistan: A Social history of broadcasting. Gazette: The International Journal for Communication Studies, 64. pp. 267-279.

Sparks, G.G. (2013). Media effects research: A basic overview. Boston, MA: Wadsworth

Stake, R. E. (1995). The art of case study research. Thousand Oaks, CA: Sage.

Surlin, S.H. (1986). Uses of Jamaican talk radio. Journal of Broadcasting \& Electronic Media, 30. pp. 459-466.

Usher, N. (2012). Marketplace public radio and news routines reconsidered: Between structures and agents. Journalism. pp.1-16. Doi:10.1177/1464884912455903

Wik, R.M. (1981). The radio in rural America during the 1920's. Agricultural History, 55. pp. 339-350.

Wolf, K.M., \& Fisk, M. (1949). The children talk about comics. In P.F. Lazarsfeld \& F.N. Stanton (Eds.). Communications Research. (1948-1949). pp. 3-50. New York, NY: Harper 


\section{Appendix A}

\section{Station owner Interview Questions}

\section{Warm up questions}

How would you describe the community? I.e. Political affiliation, religious views, economic views, social views, etc.

Probe: How would you describe your core listening audience?

How would you describe KMMR to an outside observer?

Probe: What is the history of KMMR?

Probe: How did you decide on the station format?

Probe: How does KMMR reflect the interests of the community?

Probe: How do community members see KMMR?

\section{RQ1: What gratifications do the producers of KMMR see their programs fulfilling within Malta?}

Malta residents have multiple sources for information and entertainment (television, newspapers, the internet, out of town radio stations, etc.), why do you think community members listen to KMMR?

Probe: In what ways do you think KMMR differs from other media sources? (I.e. the internet, the local newspaper/city newspapers, or cable/satellite television)

Probe: In what ways does KMMR differ from other radio stations on the Hi-Line?

Probe: What does KMMR provide listeners that they cannot get from the internet?

Do you air more locally produced programs or syndicated programs?

Probe: Do community members have a preference as to who produces the programs you air?

Probe: Are local voices on the radio important for community members?

Describe the local programs you produce. (IE Coach's Corner, Sporting Events)

Probe: What are your motivations behind creating these programs?

Probe: Why do believe community members listen to these programs?

Describe the most popular syndicated programs you broadcast. (IE Focus on the Family, ABC World News, Paul Harvey Jr, Crook and Chase)

Probe: What are your motivations behind choosing these programs?

Probe: Why do you believe community members listen these programs? 
Why do you air agricultural reports?

RQ3: How do the producers of KMMR feel improved availability of the internet has impacted gratifications sought and obtained from listening to KMMR?

In your opinion, how has access to high-speed internet impacted listenership?

Probe: What do you perceive to be the long term effects of high-speed internet on your listening audience's use of KMMR? 


\section{Appendix B}

\section{Disc Jockey Interview Questions}

\section{Warm Up}

How long have you worked at KMMR?

Probe: Why did you start working here?

How would you describe the community? I.e. Political affiliation, religious views, economic views, social views, etc.

Probe: How would you describe your core listening audience?

What is the role of KMMR within the community?

Probe: How does KMMR reflect the interests of the community?

Probe: How do community members see KMMR?

Probe: How does KMMR differ from other radio stations on the Hi-Line?

\section{RQ1: What gratifications do the producers of KMMR see their programs fulfilling within Malta?}

Malta residents have multiple sources for information and entertainment (television, newspapers, the internet, out of town radio stations, etc.), why do community members listen to KMMR?

Probe: What do community members obtain from KMMR that they cannot from the internet, outside radio stations, the local newspaper/city newspapers, or cable/satellite television?

Potential Probe: What types of information and entertainment do you think local residents look for when they listen to KMMR?

Describe the local programs you broadcast. (i.e. Coach's Corner, Sporting Events)

Probe: Why do believe community members listen to these programs?

Describe the most popular syndicated programs you broadcast. (i.e. Focus on the Family, ABC World News, Paul Harvey Jr, Crook and Chase)

Probe: Why do you believe community members listen these programs?

As a station that airs both nationally syndicated and locally produced programs and segments, do community members have a preference as to who produces the programs and segments you air?

Probe: Are local voices on the radio important to community members?

Why does KMMR still air agricultural reports? 
RQ3: How do the producers of KMMR feel improved availability of the internet has impacted gratifications sought and obtained from listening to KMMR?

In your opinion, how has access to high-speed internet impacted listenership?" Probe: What do you perceive to be the long term effects of high-speed internet on your listening audience's use of KMMR? 


\section{Appendix C}

\section{Audience Member Interview Questions}

\section{Warm up Questions}

What is your age?

What is your sex?

How long have you lived in Malta?

Probe: What is your profession?

How would you describe Malta? I.e. Political affiliation, religious views, economic views, social views, etc.

How would you describe the role KMMR plays in the community?

\section{RQ2: What gratifications are sought and obtained from KMMR by the local audience?}

How often do you listen to KMMR?

Probe: Where do you listen to KMMR at and why?

With the abundance of media choices in Malta (cable/satellite television, newspapers, internet, mp3 players), why do you listen to KMMR?

Probe: Why do you listen to KMMR over other media choices?

Probe: How does KMMR differ from other media sources? (Cable/Satellite TV, Newspapers, internet)

Probe: What local programs do you listen to and why?

Probe: What syndicated programs do you listen to and why?

Do you identify with the programs that are broadcasted on KMMR?

Do you have a preference as to who produces programs?

Are local voices on the radio important to you? 
RQ3: How do listeners of KMMR feel improved availability of the internet has impacted gratifications sought and obtained from listening to KMMR?

Describe to me your internet habits.

Probe: Can you think of instances where you have used the internet for things that you once got from the radio? 


\section{Appendix D}

\section{KMMR Owner Recruitment Script}

Hello, my name is William Pinnock, I am a former employee and currently a graduate student at Portland State University and I am conducting a study on the production and consumption of a local radio station and how the introduction of high-speed internet has impacted the audience's listening habits. Do you have a few minutes to talk to me about the study?

\section{(If no, thank them for their time and tell them to have a good day/night)}

\section{(If yes, continue)}

I am calling you today to ask if I could use KMMR, two of your disc jockeys, and yourselves for my research study. Participation in this study is voluntary and will involve a sixty minute audio taped interview about the production side of KMMR. For this study, I will be asking you questions about the production side of KMMR, specifically, choices that go into deciding what programs to air, what you believe certain programs offer the community, why you think individuals in the community listen to programs, and your thoughts on how the introduction of high-speed internet has impacted radio listenership.

Interviews will be conducted at a location and time of your choosing. There will be no monetary compensation for your participation, but I will compensate you with a copy of the finished study. Your names will appear in the finished study since as owners of a commercial radio station, your names are part of the public record. If you choose not to participate, I will not tell anyone.

Any questions so far about the study?

\section{(If yes, address questions)}

\section{(If no, continue)}

Would you like to participate in this study?

\section{(If no)}

"Thank you for your time and have a great day."

\section{(If yes, continue)}

"May I have permission to interview two of your disc jockeys?" 
(If no, thank them for their consideration)

(If yes, continue)

Conclusion

"Thank you very much for your participation in the study. When I arrive in Malta, I will contact you to set up a date and time for an interview. Have a great day/night." 


\section{Appendix E}

\section{Disc Jockey Recruitment Script}

"Hello, my name is William Pinnock, I am a former employee of KMMR and currently a graduate student at Portland State University. I am conducting a study on the production and consumption of a local radio station and how the introduction of high-speed internet has impacted the audience's listening habits. Do you have a few minutes to talk to me about the study?

\section{(If no, thank them for their time and tell them to have a good day/night)}

\section{(If yes, continue)}

"I am contacting you today to see if you would like to participate in the study I am conducting. Participation in this study is voluntary and will involve a sixty minute audio taped interview about the production side of KMMR. For this study, I will be asking you questions about the production side of KMMR, specifically, your thoughts on why people listen to KMMR, what you believe certain programs offer the community, and your thoughts on how the introduction of high-speed internet has impacted radio listenership.

Interviews will be conducted at a location and time of your choosing. There will be no monetary compensation for your participation, but your opinions and comments may have an impact on KMMR's operations.

For this study, your legal name will not appear in the study unless you agree to have it be present. If you choose not to have your name in the finished study, you and the other disc jockey will be assigned pseudonyms with no identifying characteristics present. I am doing this in order to protect you if you feel uncomfortable answering questions. Also, if you choose to participate, you can skip any questions that make you uncomfortable. If you choose not to participate, I will not tell anyone.

Any questions so far about the study?

\section{(If yes, address questions)}

\section{(If no, continue)}

Would you like to participate in this study?

(If no)

"Thank you for your time and have a great day." 


\section{(If yes, continue)}

\section{Conclusion}

"Thank you very much for your participation in the study. When would you like to set up an interview?

"Again, thank you for your time and I will see you at at . Have a nice day." 


\section{Appendix F}

\section{Recruitment Script for Malta Residents}

"Hello, my name is William Pinnock and I am a graduate student at Portland State University and I am contacting you today because I received your name from a friend of yours who told me that you would make a great participant for the study I am conducting. The research study is on the production and use of KMMR among the local listening audience and how the introduction of high-speed internet has impacted people's use of KMMR. Participation in the study is voluntary and involves no monetary compensation, but your insight could have an impact on KMMR's operations.

"If you choose to participate in this study, I will interview you for sixty minutes at a location and time of your choosing about your radio and internet use. The interview will be tape recorded. I will be asking questions examining how often you listen to the radio, why you listen to the radio, specific programs you listen to on the radio, and your use of the internet. Any answers you provide me will be kept anonymous and I will not inform anyone of your participation in the study. In the finished study, I will assign you a pseudonym and only minimal identifying information about you will be present such as age, sex, general occupation (teacher, farmer, etc.), how long you have lived in Malta, and if you live out of town or in town."

Any questions about the study or your potential role in the study?

\section{(If yes, address questions)}

\section{(If no, continue)}

Would you like to participate in this study?

(If no)

"Thank you for your time and have a great day/night."

(If yes)

"Thank you for agreeing to participate in this study. When and where would you like to conduct the interview?"

\section{Conclusion}

"Again, thank you for offering your time to participate in this study. I will see you at at . Have a great day/night." 


\section{Appendix G}

\section{Informed Consent Form \\ Portland State University}

\section{Investigator: William Pinnock}

Title of Project: "Your information station": A case study of rural radio in the $21^{\text {st }}$ century

The Communication Department at Portland State University is conducting a study on the production and consumption of radio programs in Malta, MT. Specifically, the research has three focuses: 1) how do producers see the programs they broadcast gratifying community needs, 2) what gratifications do citizens seek from their local radio station, and 3) what impact has the introduction of high-speed internet into the rural community had on gratifications sought and obtained from the local station.

\section{You must be 18 years of age to take part.}

\section{What Will I Have To Do?}

If you decide to take part in the study, I will interview you about what you feel KMMR offers the community, why you have decided on broadcasting certain programs, why you think citizens listen to those programs, and what you feel are the impacts of high-speed internet on listeners' use of KMMR and the gratifications they receive from KMMR. The interview will last 60 minutes, but it may go longer if you have a lot to say and are willing to devote more time to talking with me.

Any information that you share with me in the interview will be confidential. I will record the interview. The recording will be copied to a secure hard drive or server and the original erased from the recorder. Only I and my thesis committee will have access to the recording. I'll use that copy to take notes or transcribe the recording so I can read and reflect on our conversation.

\section{Will there be any risk or discomfort to me?}

There are minimal foreseeable risks to your participation on the study. If you feel uncomfortable answering any questions, you can skip them. If you wish to change anything you said or to stop the interview at any time, you can.

\section{How will I benefit by taking part in the research?}


For taking part in this project, you will be compensated with a copy of the study once it is completed. The finished product will be beneficial in understanding the local community and how internet has impacted listenership.

\section{What Are You Doing To Protect Me?}

This study will be using your legal name, but protecting your reputation is extremely important to me and I have taken the following measures to ensure confidentiality. - I will not tell anyone if you decide to participate or if you decide not to participate without your permission.

- You will be interviewed alone and what you say will be used only for the purpose of the current research study.

- All files concerning this research will be stored on the PSU secure network in a password protected file. A password is required for the opening of every file, folder, and document. Any notes or transcriptions will be stored in a locked area at the Communication department.

Our commitment to confidentiality is to safeguard you and others if you were to disclose something that might be illegal or damaging to the reputation of you or others.

\section{For Questions}

If you want to talk about the project and/or your interview, you can talk to the principal researcher, William Pinnock, by phone (701-330-3980) or by email (wpinnock@pdx.edu)

If you want to talk to someone about your rights as a research participant, you can contact the Human Subject Research Review Committee at the Office of Research and Sponsored Projects of Portland State University by email at hsrcc@ pdx.edu, by phone 503-725-4288 (1-877-480-4400) or by fax (503-725-8170).

You signature indicates that you have read the information above and agree to take part in an interview for the study. Please understand that you can withdraw your consent and stop the interview at anytime. You will receive a copy of this consent form for own records. 


\title{
Appendix H
}

\section{Informed Consent Form Portland State University}

\author{
Investigator: William Pinnock \\ Title of Project: "Your information station": A case study of rural radio in the $21^{\text {st }}$ \\ century
}

The Communication Department at Portland State University is conducting a study on the production and consumption of radio programs in Malta, MT. Specifically, the research has three focuses: 1) how do producers see the programs they broadcast gratifying community needs, 2) what gratifications do citizens seek from their local radio station, and 3) what impact has the introduction of high-speed internet into the rural community had on gratifications sought and obtained from the local station.

\section{You must be 18 years of age to take part.}

\section{What Will I Have To Do?}

If you decide to take part in the study, I will interview you about what you feel KMMR offers the community, how the programs you broadcast fulfill gratifications within the community, and what you feel are the impacts of high-speed internet on listeners' use of KMMR and the gratifications they receive from KMMR. The interview will last 60 minutes, but it may go longer if you have a lot to say and are willing to devote more time to talking with me.

Any information that you share with me in the interview will be confidential. I will record the interview. The recording will be copied to a secure hard drive or server and the original erased from the recorder. Only I and my thesis committee will have access to the recording. I'll use that copy to take notes or transcribe the recording so I can read and reflect on our conversation.

\section{Will there be any risk or discomfort to me?}

There are some foreseeable risks to your participation on the study. There is a potential risk that expressing opinions about KMMR may impact your employment. There is a potential risk to your reputation from expressing opinions about KMMR. There is a risk that you may feel uncomfortable answering personal questions, questions about the community, or questions about KMMR. If you feel uncomfortable you can skip a 
question at any time. If you wish to change anything you said or to stop the interview at any time, you can.

\section{How will I benefit by taking part in the research?}

For taking part in this project, you will be compensated with a copy of the study once it is completed. The finished product will be beneficial in understanding the local community and how to serve their needs.

\section{What Are You Doing To Protect Me?}

This study will require you and the other disc jockey to agree that you are willing to have your names and shifts appear in the finished product. Without the consent of both of you, you will be assigned a pseudonym, your shift will not be disclosed, and minimal identifying information will not be disclosed. This will be done to protect the identity of disc jockeys who do not feel comfortable disclosing their personal information.

I will not tell anyone if you decide to participate or if you decide not to participate without your permission.

You will be interviewed alone and what you say will be used only for the purpose of the current research study.

All files concerning this research will be stored on the PSU secure network in a password protected file. A password is required for the opening of every file, folder, and document. Any notes or transcriptions will be stored in a locked area at the Communication department.

Our commitment to confidentiality is to safeguard you and others if you were to disclose something that might be illegal or damaging to the reputation of you or others.

\section{For Questions}

If you want to talk about the project and/or your interview, you can talk to the principal researcher, William Pinnock, by phone (701-330-3980) or by email (wpinnock@pdx.edu)

If you want to talk to someone about your rights as a research participant, you can contact the Human Subject Research Review Committee at the Office of Research and Sponsored

Projects of Portland State University by email at hsrcc@ pdx.edu, by phone 503-725-4288 (1-877-480-4400) or by fax (503-725-8170). 
You signature indicates that you have read the information above and agree to take part in an interview for the study. Please understand that you can withdraw your consent and stop the interview at anytime. You will receive a copy of this consent form for own records. 


\section{Appendix I}

\section{Informed Consent Form \\ Portland State University}

\section{Investigator: William Pinnock}

Title of Project: "Your information station": A case study of rural radio in the $21^{\text {st }}$ century

The Communication Department at Portland State University is conducting a study on the production and consumption of radio programs in Malta, MT. Specifically, the research has three focuses: 1) how do producers see the programs they broadcast gratifying community needs, 2) what gratifications do citizens seek from their local radio station, and 3) what impact has the introduction of high-speed internet into the rural community had on gratifications sought and obtained from the local station.

\section{You must be 18 years of age to take part.}

\section{What Will I Have To Do?}

If you decide to take part in the study, I will interview you about what you feel KMMR offers the community, why you listen to KMMR and what gratifications you receive from KMMR, and how has the introduction of high-speed internet into Malta impacted your listening habits of KMMR. The interview will last 60 minutes, but it may go longer if you have a lot to say and are willing to devote more time to talking with me.

Any information that you share with me in the interview will be confidential. I will record the interview. The recording will be copied to a secure hard drive or server and the original erased from the recorder. Only I and my thesis committee will have access to the recording. I'll use that copy to take notes or transcribe the recording so I can read and reflect on our conversation.

\section{Will there be any risk or discomfort to me?}

There are some foreseeable risks to your participation on the study. There could be a potential risk to your reputation if you express opinions about KMMR or the community. There could be a potential risk that you could feel uncomfortable with questions regarding your occupation, your thoughts on the community, your media habits, and your thoughts on KMMR.

\section{How will I benefit by taking part in the research?}


For taking part in this project, you will be given an opportunity to share your thoughts and feelings about KMMR and your statements could help improve KMMR's function within the community.

\section{What Are You Doing To Protect Me?}

This study will not be using your legal name. To protect your identity, I will be assigning you a pseudonym and minimal identifying information will be made relevant (age, gender, generalized occupation, whether you live in or out of town, etc.).

I will not tell anyone if you decide to participate or if you decide not to participate.

You will be interviewed alone, in a location of your choosing, at a time of your choosing, and what you say will be used only for the purpose of the current research study.

All files concerning this research will be stored on the PSU secure network in a password protected file. A password is required for the opening of every file, folder, and document. Any notes or transcriptions will be stored in a locked area at the Communication department.

My commitment to confidentiality is to safeguard you and others if you were to disclose something that might be illegal or damaging to the reputation of you or others.

\section{For Questions}

If you want to talk about the project and/or your interview, you can talk to the principal researcher, William Pinnock, by phone (701-330-3980) or by email (wpinnock@pdx.edu)

If you want to talk to someone about your rights as a research participant, you can contact the Human Subject Research Review Committee at the Office of Research and Sponsored Projects of Portland State University by email at hsrcc@ pdx.edu, by phone 503-725-4288 (1-877-480-4400) or by fax (503-725-8170).

You signature indicates that you have read the information above and agree to take part in an interview for the study. Please understand that you can withdraw your consent and stop the interview at anytime. You will receive a copy of this consent form for own records. 